\title{
دراسة تحليلية لمضمون قضايا الإعاقة في الصحافة الجامعية
}

\author{
الباحث \\ د/ عبد الباقي محمد عرفة سالم \\ أستاذ مساعد كلية التربية بالمجمعة مبلة
}


دراسة تحليلية لمضمون قضايا الإعاقة في الصحافة الجامعية

د/ عبد الباقي محمد عرفة سالم 


\section{مستخلص:}

هدفت الدراسة الحالية إلى تحليل مضمون الموضوعات المتعلقة بقضايا الإعاقة في الصحافة الجامعية التي تصدر عن بعض الجامعات العربية ، وتحديد أبرز قضايا الإعاقة وكيف تم تناولها و جوانب القوة والضعف فيها، واستخدمت الدراسة استمارة تحليل المضمون لنديه

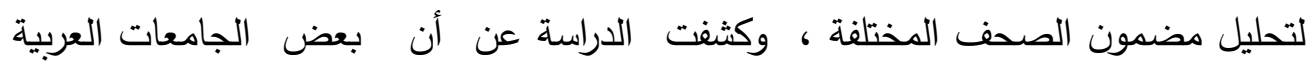

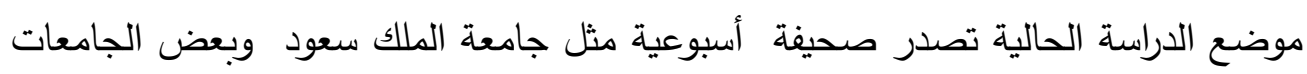

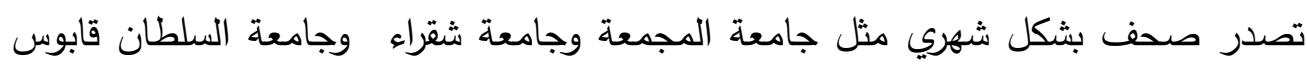
وجامعة البحرين وبعض الجامعات تصدر صحف ربع سنوية مثل جامعة بيروت العربية

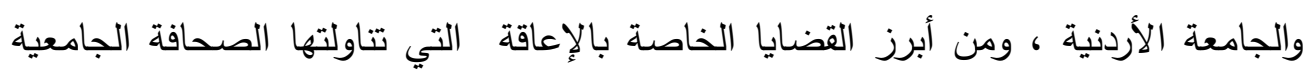

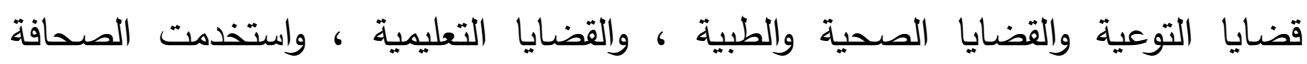

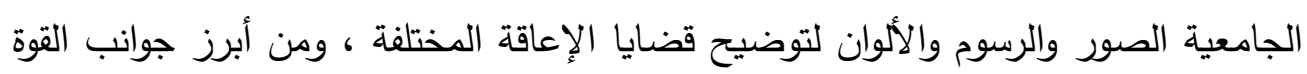

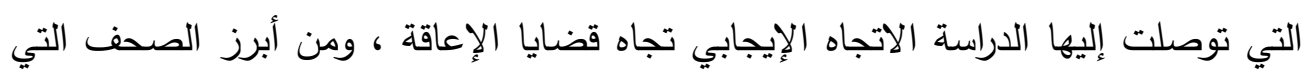

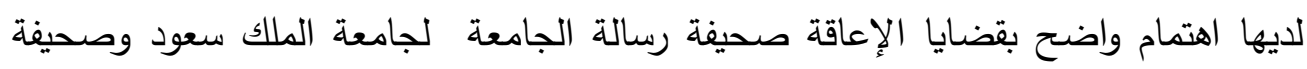

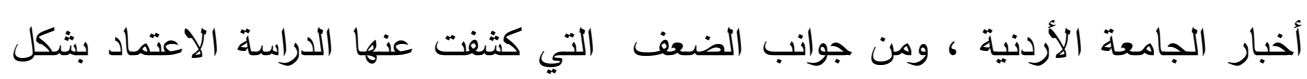
كبير على التقارير والأخبار الصحفية وقلة التحقيقات والمقالات في تتاول قضايا الإعاقة المختلفة الكلمات المفتاحية قضايا الإعاقة، الصحافة الجامعية 


\section{An analytical study of the content of disability issues in the university press}

\section{Abstract:}

The present study aimed to analyze the content of topics related to disability in the university press issued by some Arab universities issues, and to identify the most prominent disability issues and how they were addressed and the strengths and weaknesses, the study used content analysis form to analyze the content of the various newspapers, the study revealed that some Arab universities the subject of the current study, published a weekly newspaper such as King Saud University and some universities Newspapers are issued on a monthly basis, such as bundled University and the University of blonde and Sultan Qaboos University and the University of Bahrain and some universities issued Newspapers quarterly like Beirut Arab University and the University of Jordan, and the most prominent disability addressed by university journalism education issues issues health and medical issues, and issues of education, university press and used the pictures, drawings and colors to illustrate the various disability issues, and highlighted the strengths of the study are positive trend towards disability issues, and the most prominent newspapers, which have a clear interest in disability issues daily mission of the university to the University of King Saud and newspaper University News Jordan, and the weaknesses revealed by the study rely heavily on press reports, news and the lack of investigations and articles in dealing with various disability issues.

Key words

Disability Issues, University Press 
يقاس تقدم الأمم بما يقدم لذوي الإعاقة من تشريعات وقوانين وخدمات ورعاية

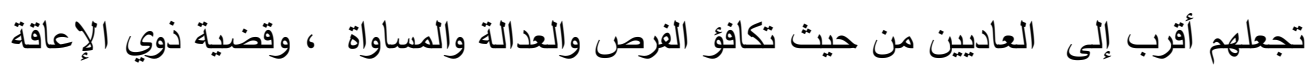
من القضايا المجتمعية الهامة حيث تمثل نسبة ذوي الإعاقة في المجتمع بشكل عام مالا يقل عن 10\% من عدد السكان ، أي أن عدد ذوي الإعاقة في الدول العربية تجاوز 35

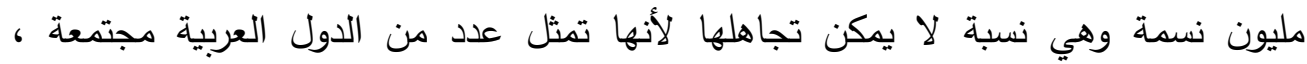

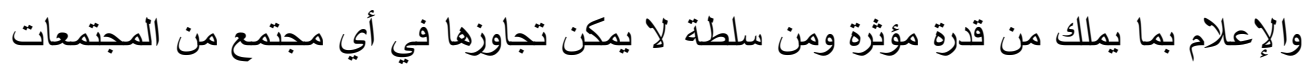

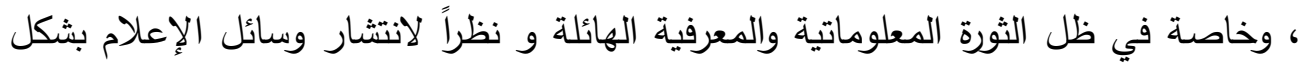
يمكنها من التأثير المباشر في اتجاهات المجتمع وتثكيل فكر ووعي ووجدان المجتمع تجاه القضايا الخاصة بذوي الإعاقة ؛ومن هنا لابد من تفعيل دور الإعلام الجامعي بكافة أثكاله

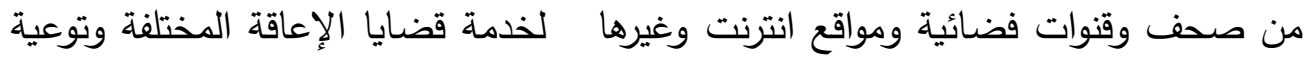

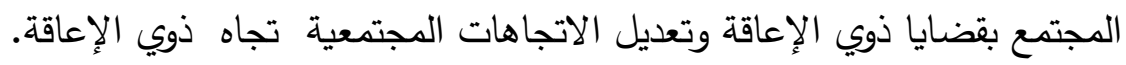

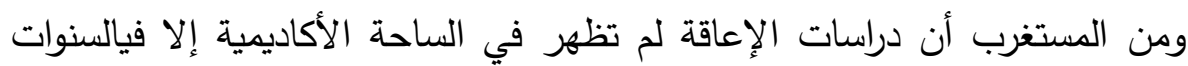
الأخيرة من القرن الماضي، رغم أن الإعاقة موجودة في الإنسان سواء كانت إعاقة مؤقتة أو إلى

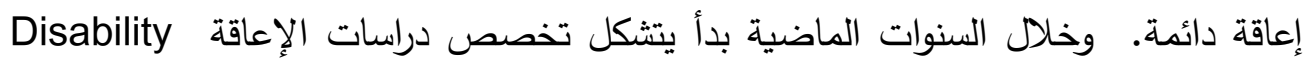
Studies ودراسات التأهيل وغيرها من التخصصات (Harpe,2005) والباحث في قضايا الإعاقة التي تتناولها الصحافة يجد أن هناك ضعف شدئ شديد من حيث الكم والكيف في تتاول الصحافة لقضايا ومشكلات المعاقين.ورغم الاهتمام المتزايد خلال السنوات

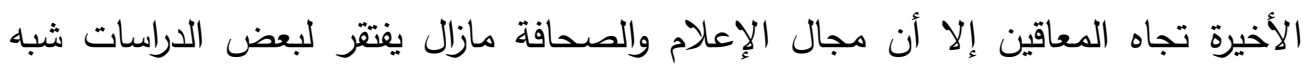

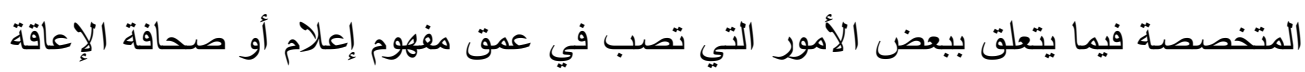
(الملتقى السابع للجمعية الخليجية 2007) والإعلام هو أحد التخصصات التي ينبغي أن يقترب من دراسات الإعاقة والتربية الخاصة، لأهمية وسائل الإعلام في كثير من قضايا الإعاقة، وفي مقدمتها قضية التوعية، 
دا دافة الجامعة الباقي محمد عرفة سالم

وقضية الاتجاهات السلبية التي تتراكم لتثكل عقبات وصعوبات تواجه المعاقين ومؤسسات الإعاقة في تحقيق أهدافهم في تحسين صورة المعاقين في المجتمع (القرني، 2007)

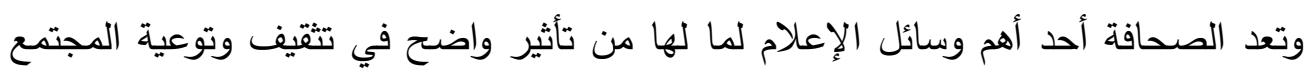
بمختلف القضايا والمشكلات،فالصحافة تعمل على تعديل اتجاهات المجتمع تجاه القضايا

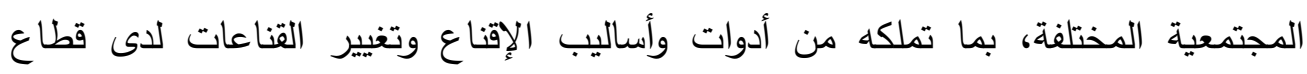
عريض من شرائح المجتمع من خلال التقارير والتحقيقات التي ترصد القضايا المختلفة ولهات وخاصة قضايا ذوي الاحتياجات الخاصة في مختلف الجوانب الصحية والنفسية والاجتماعية والتعليمية.

كما تمثل الصحافة باعتبارها وسيلة من وسائل الإعلام أحد المصادر الرئيسية التي

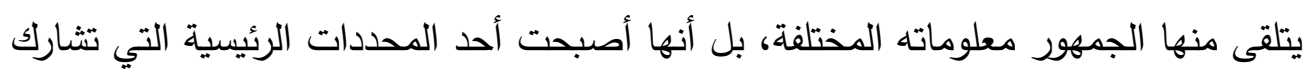
في تحديد ملامح سلوك الجمهور وقيمة وعاداته، وفي هذا الصدد تتضح أهمية المدخل

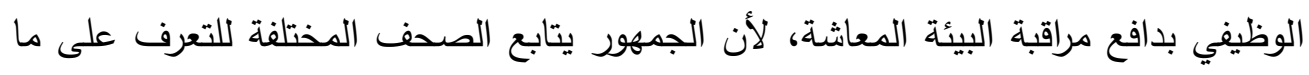

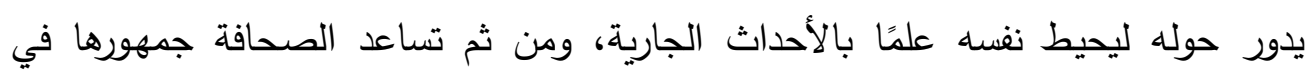
تثكيل آرائهم حول القضايا المثارة من خلال النظام المعلوماتي الذي تقدمالها على تلى صفحاتها (سها فاضل ، 2002) ولعل من المجالات التخصصية التي لم تحظ حتى الآن بالاهتمام الواجب صحافة

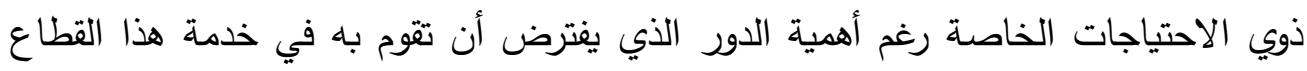

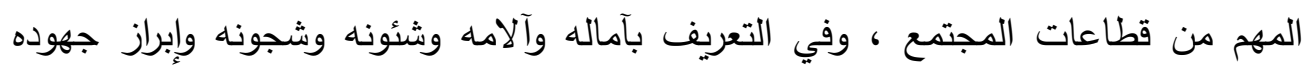

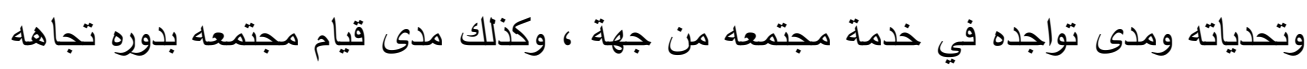

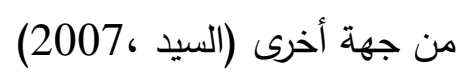

وفي دراسة عن الصحافة والإعاقة أكدت الدراسة على ضعف اهتمام الصحافة العربية بقضايا

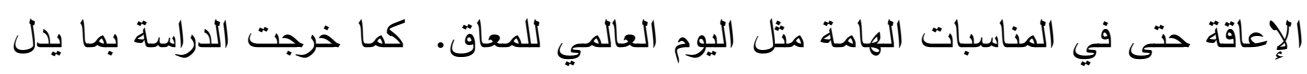

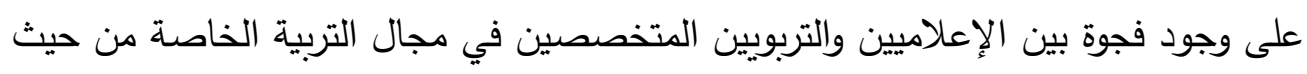

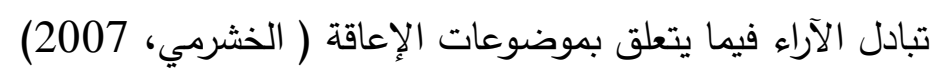


والتعليم الجامعي يمثل حجر الزاوية في التتمية والتتوير وتثقيف المجتمع بالقضايا المختلفة ومن ضدنها قضايا ذوي الإعاقة، والجامعات العربية لها إصدارات صحافية عدة، تلعب دورا كبيرا في تعريف المجتمع الجامعي والمجتمع المحلي بأنشطة الجامعة ودورها في خدمة المجتمع، وعدد كبير من الجامعات في مختلف البلدان العربية لها إصدارات صحفية منها بهاتها الأسبوعية ومنها الثهرية ومنها الربع سنوية. وانطلاقا مما سبق تحاول الدراسة الحالية تحديد دور الصحافة الجامعية في خدمة قضايا لهائ الإعاقة والععل على تفعيل هذا الدور من خلال المقترحات المختلفة لتفعيل دور الصحافة الجامعية في خدمة قضايا المعاقين.

مشكلة الاراسة:

تكمن مشكلة الدراسـة في الضعف الواضـح في الدور الذي يلعبه الإعلام العربي

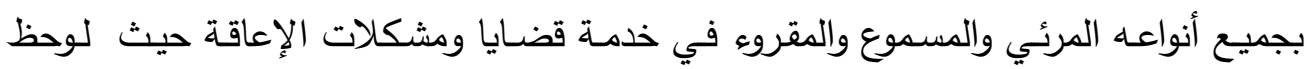
ضـفف التغطيـة الإعلاميـة حيث لا توجد قنوات أو برامج تستمر في التغطيـة وإنمـا تكون

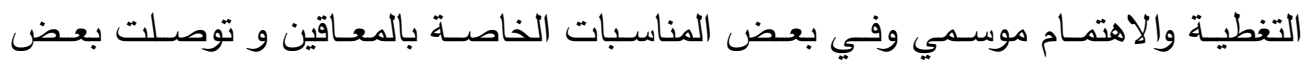

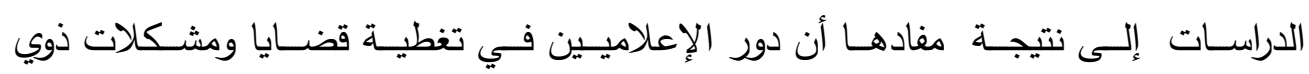

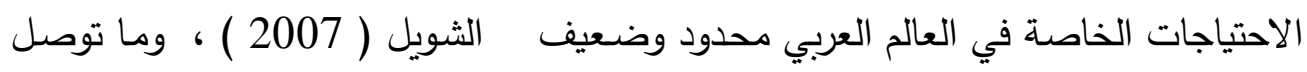
إليه الملتقى السابع للجمعية الخليجية للإعاقة (الإعلام والإعاقة ) المنعقد في مملكة البحرين

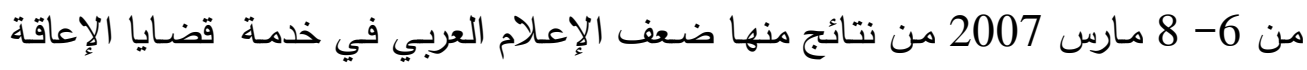
المختلفة ووجود اهتمام عام محدود لدى الصحافة العربية بقضايا الإعاقة حتى في المناسبات

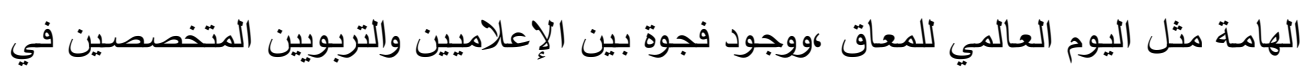

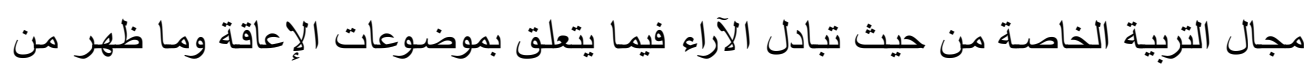
المسميات السلبية والمصطلحات النمطية عن ذوي الاحتياجات الخاصة في الصحافة العربية.

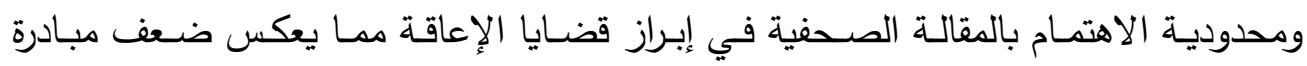

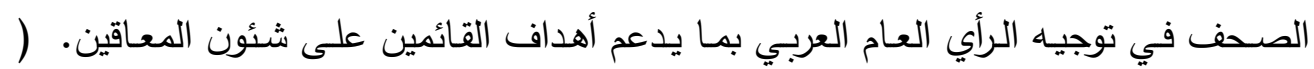

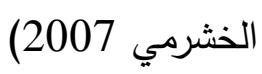


ومن هنا تأتي مشكلة الدراسة الحالية في البحث عن دور الصحافة الجامعية في تغطية

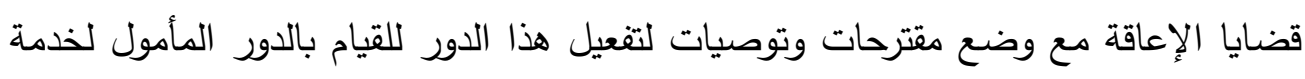

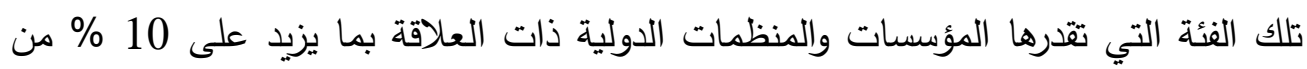
مجموع السكان في أي مجتمع من مجمل حالات الإعاقة (الخطيب، والحديدي 2015).

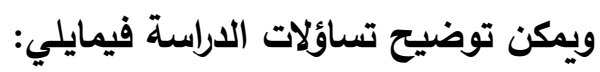

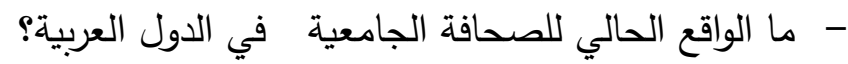

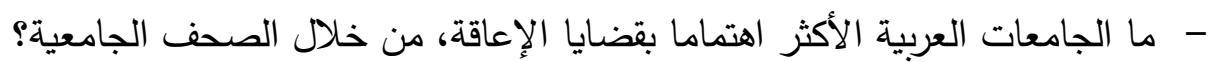

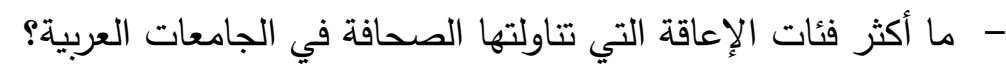
- كيف يتم إبراز قضايا الإعاقة فنيا في الصحافة الجامعية في الدول العربية؟

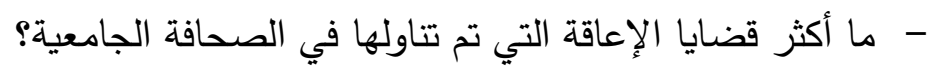
- ما الكيفية التي تناولت بها الصحافة الجامعية للقضايا المتعلقة بالإعاقة من حيث موقع المادة الصحفية واستخدام الصور والألوان؟ مالكئه

- ما جوانب القوة والضعف في تتاول الصحافة الجامعية لقضايا الإعاقة؟ - - ما أهم المقترحات التي يمكن أن تفعل دور الصحافة الجامعية في خدمة قضايا الإعاقة؟

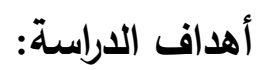

يهدف البحث الحالي إلى تتاول قضية من أهم القضايا المجتمعية وهي قضية الإعاقة وكيفية تناولها من خلال الصحافة الجامعية بموضوعاتها ومشكلاتها المختلفة،وتقوم الدراسة بتحليل مضمون موضوعات وقضايا الإعاقة في الصحف الجامعية الصادرة عن الجامعات في الدول العربية مع وضع مقترح لتفعيل دور الصحافة الجامعية في تتاولها لموضوعات وقضايا الإعاقة في الدول العربية ومن أهداف الدراسة مايلي: - التعرف على الواقع الحالي للصحافة الجامعية تجاه خدمة قضايا الإعاقة. - التعرف على أبرز قضايا الإعاقة التي تتاولتها الصحافة في الجامعات العربية. - - التعرف على الكيفية التي تتاولت بها الصحافة الجامعية للقضايا المتعلقة بالإعاقة. - مناقثة جوانب القوة والضعف في تتاول الصحافة الجامعية لقضايا الإعاقة. - - وضع مقترحات لتفعيل دور الصحافة الجامعية في خدمة قضايا الإعاقة. 
للبحث أهمية تطبيقية في التعرف على دور الإعلام الجامعي في خدمة قضايا الإعاقة وذلك

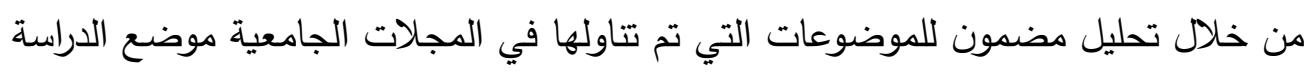
،وللدراسة أهمية كذلك في تثخيص الواقع الحالي للإعلام الجامعي في تتاول قضايا الإعاقة من حيث تحديد أبرز جوانب القوة وجوانب الضعف والكيفية التي تم بها تتاول قضايا الإعاقة مع تحديد أبرز قضايا الإعاقة في الصحافة الجامعية ،و الدراسة الحالية ستقوم بوضع مقترحات عن كيفية تفعيل دور الإعلام الجامعي في الجامعات العربية المختلفة لخدمة قضايا الإعاقة.

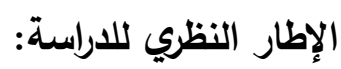
يتناول الإطار النظري أهم قضايا الإعاقة ودور الصحافة الجامعية في تتاولها. ا - - مضايا الإعاقة

من خلال البحث في أدبيات التربية الخاصة وجدت الدراسة الحالية عددا كبيرا من

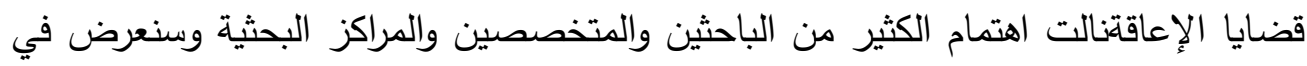

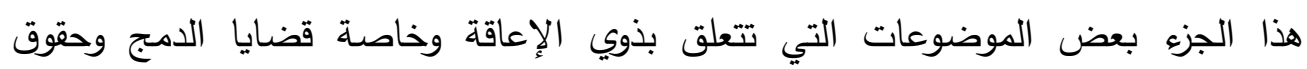

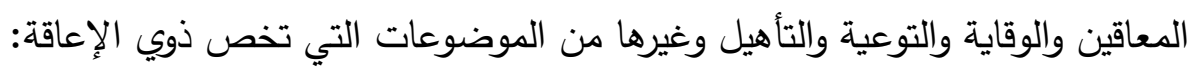
r - ب - دمج ذوي الإعاقة: وتعتبر قضية الدمج من أكثر القضايا إثارة للجدل في أوساط التربية الخاصة، وذلك لتباين الآراء بين مؤيد ومعارض، وقد ظهرت هذه القضية بشكل واضح في التربية الخاصة

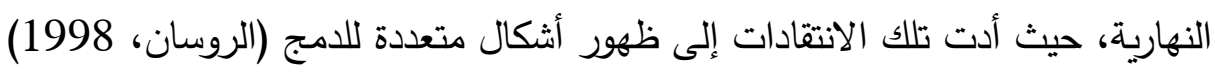
والدمج هو أحد الاتجاهات الحديثة في التربية الخاصة ويعرفه هيجارتي وآخرون بأنه "تعلم الأطفال ذوي الاحتياجات الخاصة في المدارس العادية. بحيث يتم تزويدهم ببيئة طبيعية تضم أطفالاً عاديين، وبذلك يتخلصون من عزلتهم عن المجتمع(Hegarty,1981). ويحقق الدمج قيم العدالة الاجتماعية وكذلك يحقق الدمج مبدأ تكافؤ الفرص بين جميع عزيع الأفراد

(Fara.M.and others, 2006) 
إن قضية الإعاقة ورعاية المعاقين وأسرهم، وتوعية المجتمع بقضايا الإعاقة

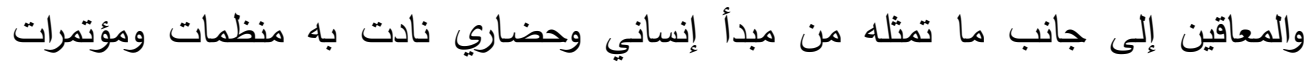
المجتمع الدولي، فهي من القضايا التي نادت الشريعة الإسلامية برعايتهم والاهتمام بهم وكفالتهم منذ أكثر من 1400 عام (عرفة ،2012) وعرف إيهاب البيلاوي التوعية بأنها "مجموعة المعلومات والمهارات والخبرات التي يتم عاتمات إكسابها لأفراد المجتمع بشكل عام ولذوي العلاقة بموضوع الإعاقة والمعوقين على وجه ولهي

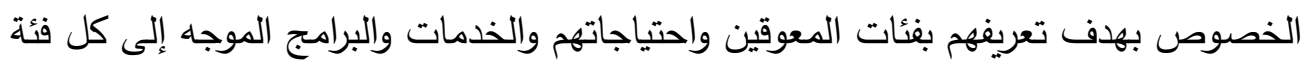
من فئات الإعاقة وطرق الوقاية من الإعاقة " (البيلاوي، 2011)

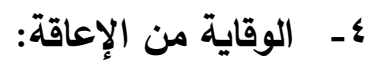

وقد تبنت جهات عديدة ومنها منظمة الصحة العالمية تعريفاً للوقاية "وهي مجموعة الاعة العاته

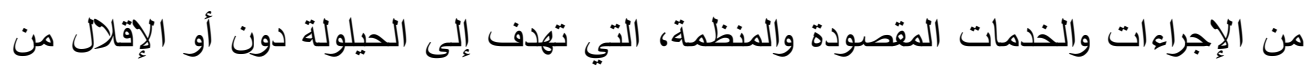

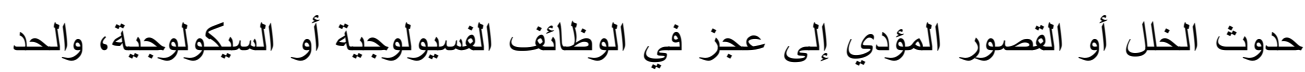

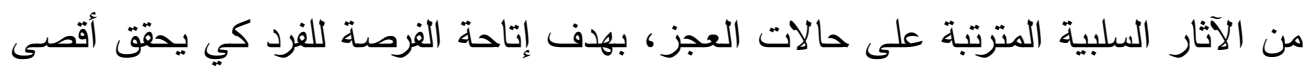

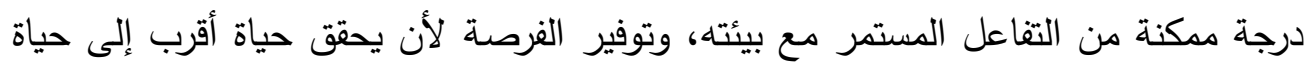
العاديين، وقد تكون تلك الإجراءات والخدمات ذات طابع طبي أو اجتماعي أو تأهيلي أو أو الى تربوي".

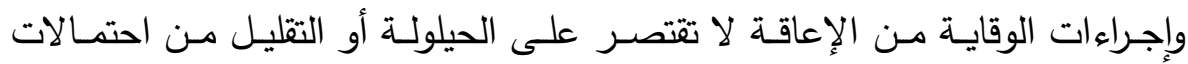

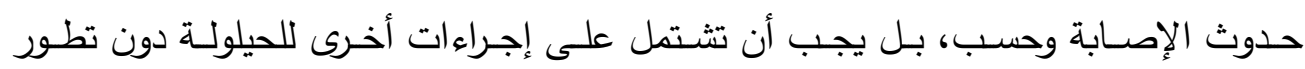

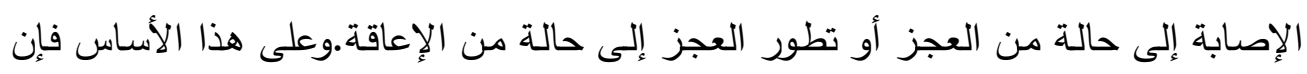

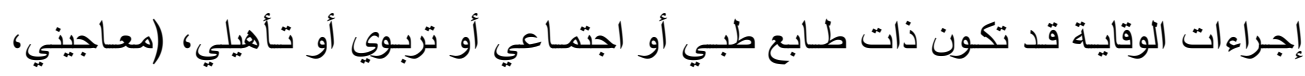

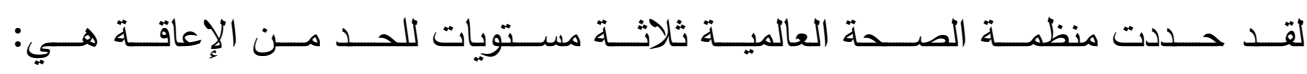
المستوى الأول : المات إزالـة العوامل المسببة للإعاقة، وتتضـمن إجراءات صـية واجتماعية مختلفة كالتحصينات

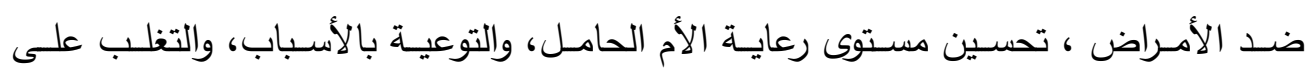
مشكلات الفقر . مـراص ، 


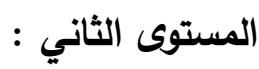

خدمات الكثف عن الإصـابات ومواطن الخلل وإجراءات التدخل المبكر لـنـع المضـاعفات

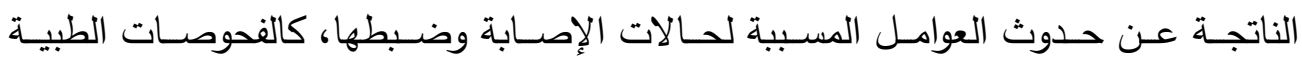
والاختبارات المختلفة للكثف المبكر عن حالات الخلل الفسيولوجي والعيوب التشريحية أو الوضئ

الاضطرابات النفسية.

المستوى الثالث : (المرابات

إجراءات التقليل من الآثار السلبية المترتبـة على حـالات القصـور والعجز، والتخفيف مـن

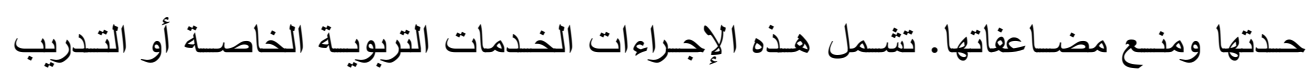

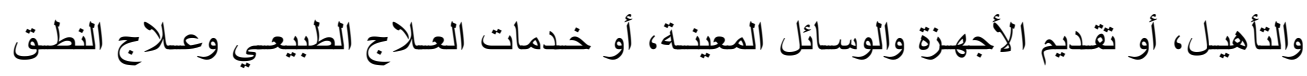
والكلام وغيرها.

\section{هـ قضية تأهيل المعاقين:}

فالتأهيل هو تلك العملية المنظمة والمستمرة والتي تهدف إلى إيصال الفرد المعوق

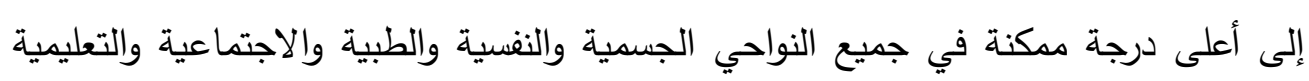
وغيرها

والتي تتم بمشاركة الثخص ذوي الإعاقة وأسرته في بيئته المحلية بهدف الوصول بالإفراد ذوي الإعاقة إلى أفضل درجة ممكنة من النواحي الطبية والاجتماعية والنفسية والتربوية والاقتصادية

لذا يعتبر التأهيل عملية شاملة مساعدة تهدف لوصول الفرد المعوق إلى أعلى درجة ممكنة

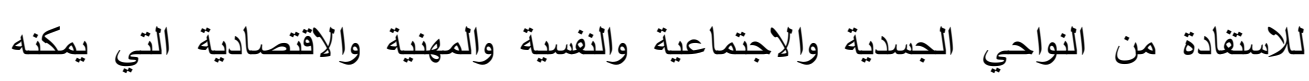

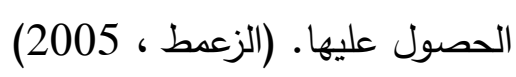

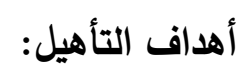

1-توفير الفرص والإمكانات اللازمة في مجال العلاج والرعاية الطبية والنفسية والاجتماعية سواء من خلال الأسرة أو المؤسسات المتخصصة. 2-توسيع مجالات التدريب والتأهيل المني والعمل على تطوير مجالات هذا التدريب بما يتتاسب مع ميول واستعدادات وقدرات المعوقين. 
3-تمكين المعوقين من عملية الاندماج الاجتماعي واكتساب الثقة بأنفسهم والعمل على زيادة ثقة المجتمع واتجاهات أفراده نحوهم.

4-تأمين الثخص المعوق ضد حالات العجز والثيخوخة والبطالة. 5-توفير فرص الوقاية والتحصين والعلاج من الأمراض السارية والمعدية المستوطنة في البيئات الاجتماعية والإنسانية المختلفة.

6-توفير فرص العمل والتثغيل في مختلف قطاعات النثاط الاقتصادي والاجتماعي الأية

$$
\text { والحكومي والخاص. }
$$

7-تهيئة كافة المجالات والوسائل المناسبة للنمو وذلك للوصول إلى درجة معينة من الإثباع

$$
\text { الثقافي والترويحي. }
$$

8-مساواة المعوقين مع غيرهم من أقرانهم غير المعوقين بصفتهم مواطنين وذلك بوضع السياسات التي تكفل حقوقهم.

9-إتاحة فرص التعليم للمعوقين بما يتاسب مع كل فئة من فئات المعوقين (الزارع،2006) צ- - حقوق المعاقين:

الحديث عن حق ذوي الإعاقة من أهم الموضوعات التي يقاس عليها مدى تقدم المجتمعات

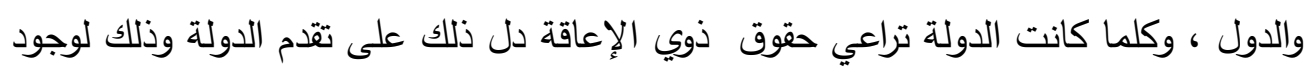

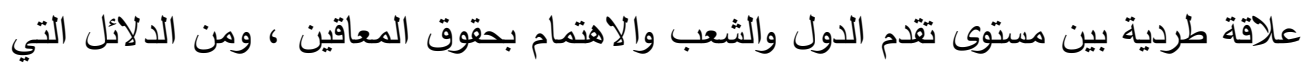
يشهدها العالم على مدى أهمية قضايا حقوق المعاقين هي كثرة المواثيق والإعلانات

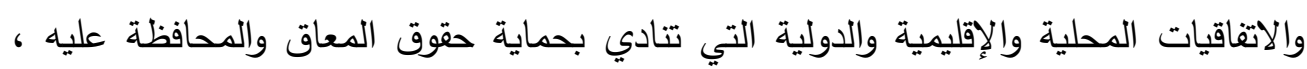
والمشكلة الكبرى التي يعاني منها المهتمين بحقوق المعاقين ليست التشريعات والاتفاقيات فهي كثيرة ولكن المشكلة في تطبيق هذه التشريعات والاتفاقيات والقوانين المنبثقة عنها.

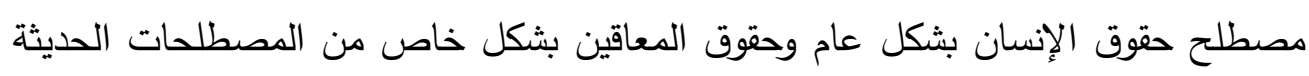

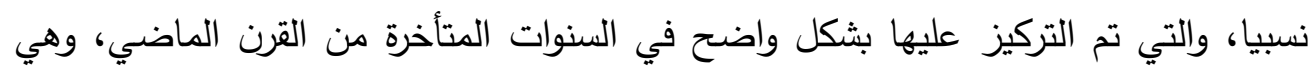
نتاج لتراكمات تاريخية طويلة، وإن كانت التشريعات الدينية زادت من مكانتهات ولتها وأهميتها

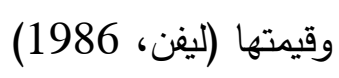
تعريف حقوق المعاقين 
هي الحقوق التي اعترفت بها التشريعات والمواثيق الدولية والقوانين للشخص المعاق من حقوق شخصية واجتماعية واقتصادية وسياسية وغيرها من الحقوق، بالإضافة لحقوق الإنسان العادي التي يشترك المعاق فيها، وقد صدر الإعلان العالمي لحقوق الإنسان 1948

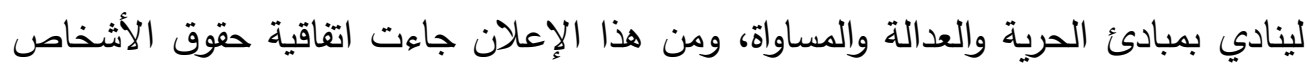

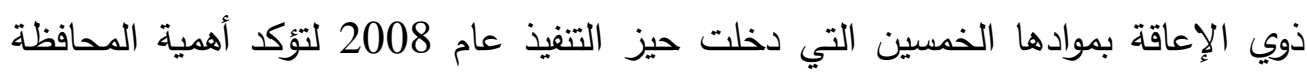
على رعاية المعاقين (القحطاني، 2010)

ومن أهم مبادئ اتفاقية حقوق الأثخاص ذوي الإنيه الإعاقة

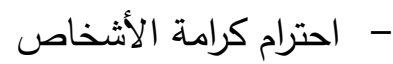
- - - مدم التمييز - - احترام الفوارق وقبول الأشخاص ذوي الإعاقة كجزء من التتوع البشري

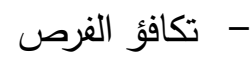

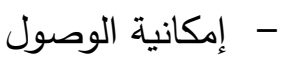

- احترام القدرات المتطورة للأطفال ذوي الإعاقة واحترام حقهم في الحفاظ على هويتهم

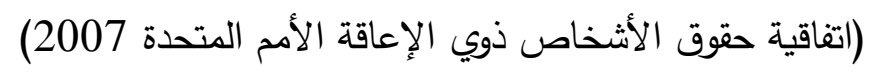
الإعلام والإعاقة:

- ولقد كان الإعلام العربي إلى وقت قريب فيما يري كل من عمر خضر (1993) بعيداً

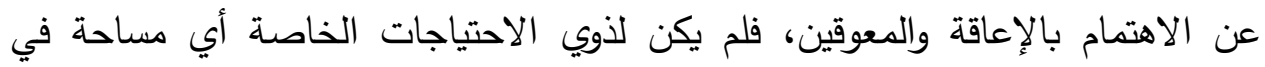

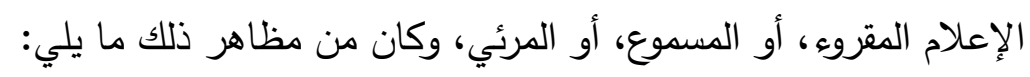

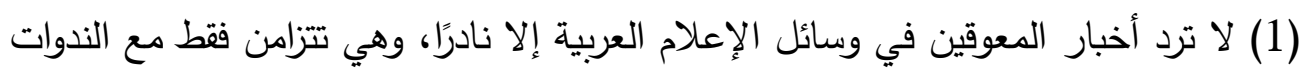

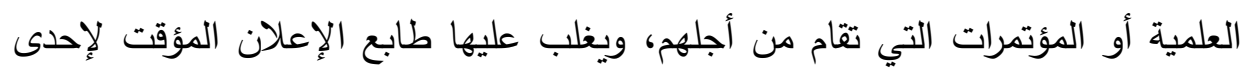

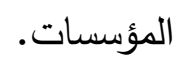

(2) رغم تدفق الأخبار بكثافة من وكالات الأنباء العالمية عن المعوقين وحقوقهم فإن ما ينشر منها في الوطن العربي أو يبث أو يذاع يمكن اعتباره محدودًا للغاية. (3) تدني حجم ونوعية البرامج الموجهة عن الإعاقة والمعوقين في وسائل الإعلام العربية فهي تأتي غالباً في صورة إعلانات عامة. 
(4) أعداد محدودة من الإصدارات الخاصة عن المعوقين والتي تصدر في المنطقة العربية

وهي تحتاج لاعم كامل حتى تصل إلى كل الناس، وليس لإعداد محدودة فقط.

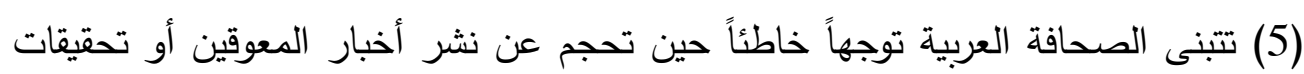

$$
\text { عن واقعهم. (خضر (1993) }
$$

- ملعل أهم أسباب الاهتمام بقضايا الإعاقة في الصحافة مايلي:

- قلة الدراسات والبحوث المتعلقة بإعلام وصحافة المعاقين خاصة الصحافة الإبات المكتوبة. - وجود نسبة كبيرة من الأشخاص المعاقين علي مستوي الخليج العببي والذين هم بحاجة ماسة إلي صحافة متخصصة لمتابعة كل ما يتعلق بهم وتوعية مجتمعاتهر. - نقص كبير في المجال التوعوي والتثقيفي بواسطة الصحافة الدكتوبة ومحدودية انتثارها محلياً وخليجياً. - أهمية البحث في إبراز جهود الدول في مجال صحافة المعاقين، والتعرف علي واقع هذه الصحافة والعوائق التي تقف حاجزاً أمام انتثار واستمرارية وجود صحافة متخصدة صدصة

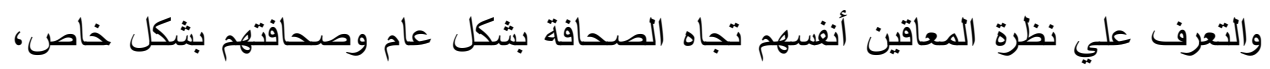
وقد تساعد نتائج هذا البحث في تأهيل المجتمع صحافيا وإعلاميا مما يساعد في التقليل

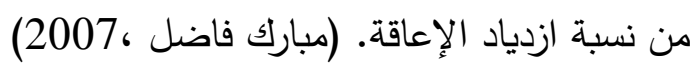

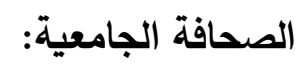

الصحافة الجامعية تُعد أحد مكونات الصحف الوطنية في الدول المتقدمة، وتُشكّل نموذجاً من النماذج التي تتمازج بها المعرفة الأكاديمية مع الممارسة المهنية المبنية على أسس علمية راسخة في تخصص الصحافة والإعلام، والصحف الجامعية هي بالآلاف في مجتمع مثل الولايات المتحدة الأمريكية التي قد تصل فيها الجامعات إلى عشرة آلاف جامعة أو كلية أو أكثر من ذلك. ولهذا فدراسة الصحافة الوطنية يجب أن تمر من خلال دراسة الصحافة

$$
\text { الجامعية (على القرني ،2014) }
$$

وتقوم الصحافة الجامعية بدور رئيسي في التواصل مع طلاب الجامعة من خلاد

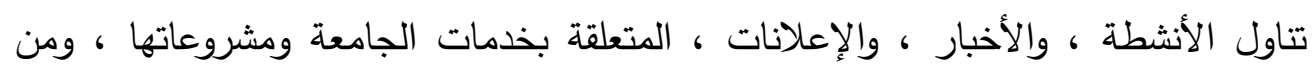

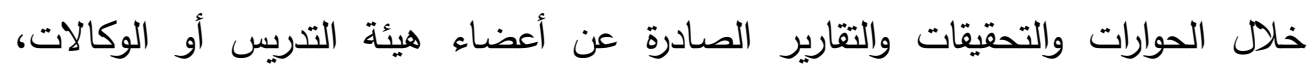


والعمادات، والإدارات المختلفة .وهناك صحف جامعية تصدر من خلال طلاب الجامعة وأعضاء هيئة التدريس وهيئة تحرير متخصصة أو من أساتذة الإعلام ، وهناك صحف أخدى تصن

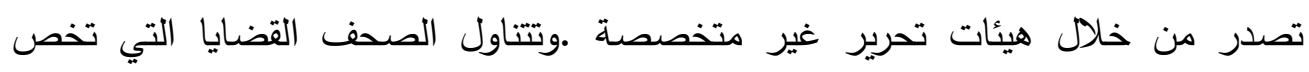
الطلاب وأعضاء هيئة التدريس ومجتمع الجامعة ودور الجامعة في خدمة المجتمع المحلي

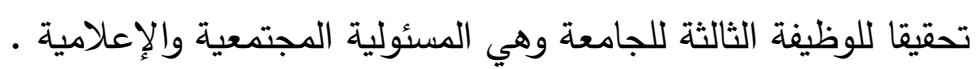

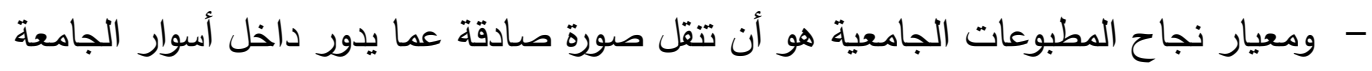
إلى المجتمع الأوسع بنظرة شاملة تؤمن بالدور الإيجابي للإعلام وتحترم المتلقي وأن تدعم رسالة الجامعة تجاه المجتمع (العبدلي ، 2011)

مصطلحات الاراسة: تحليل المضمون

عرف بيرلسون:Berelson) تحليل المضمون بأنه هو أحد الأساليب البحثية التي تستخدم في وصف المحتوى الظاهر أو المضمون الصريح للمادة الإعلامية وصفاً موضوعيا منتظما

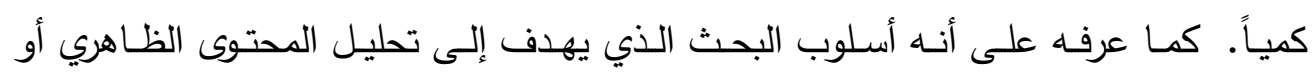

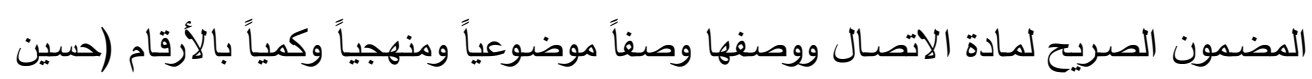

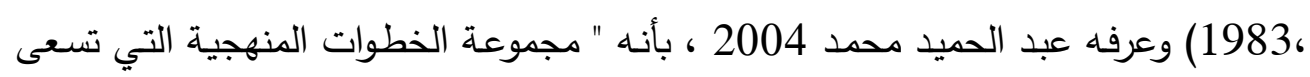

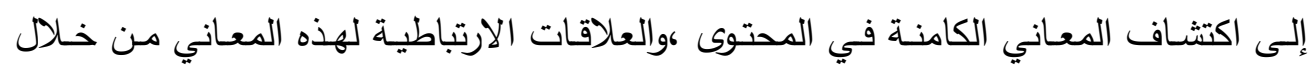
البحث الكمي الموضوعي ،والمنظم للسمات الظاهرة في هذا المحتوى" (محمد ،2004 ) 
الصحف الجامعية هي تلك الدوريات النوعية الموجهة إلى الجمهور الجامعي بشكل أساسي،

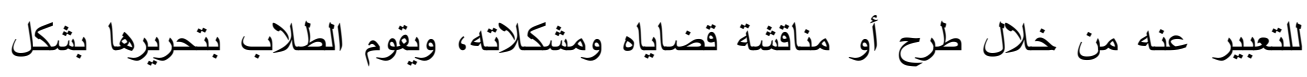

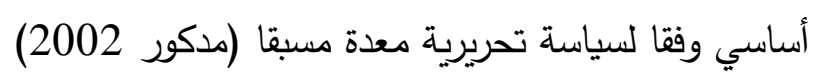
الصحف الجامعية من وسائل الاتصال النوعية التي تهتم بجماعات محلية لتحقيق أهداف معينة،وهي صحف متخصصة عامة تركز على نوع معين من المضمون وهو الخاص بالقضايا الجامعية، وتتوجه لجمهور خاص هو الجمهور الجامعي (عبدالمجيد 1997) التعريف الإجرائي: يقصد بالصحافة الجامعية في هذه الدراسة "هي الصحف والنشرات، والمجلات التي

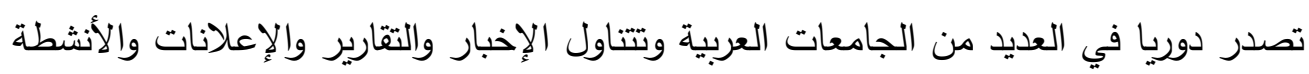

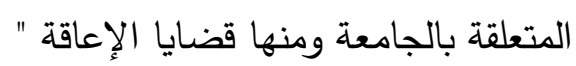
قضايا الإعاقة: عرفت سحر الخشرمي 2007، قضايا الإعاقة بأنها " كل ما يطرح من موضوعات حول الاحتياجات الخاصة والمعوقين" ويعرفها البحث الحالي بأنها "هي الموضوعات والمشين وآثكلات المتعلقة بذوي الإعاقة والتي تتتاولها الصحف الصادرة عن بعض الجامعات العربية "

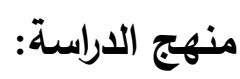
استخدمت الدراسة المنهج الوصفي التحليلي بما يتضمنه من أسلوب تحليل المضمون، حيث يعتبر أسلوب تحليل المضمون من أحد الأساليب البحثية شائعة الاستخدام

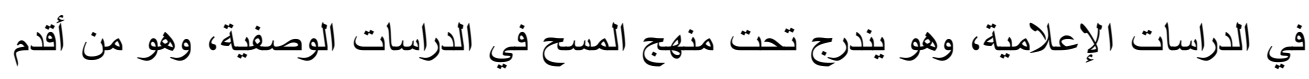

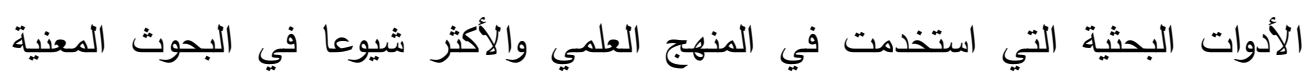

$$
\begin{aligned}
& \text { بالرسالة الإعلامية (حسونة،2014) } \\
& \text { إجراء ات الدراسة: }
\end{aligned}
$$

- إعداد استمارة تحليل المضمون والتحقق من صدق وثبات الاستمارة.

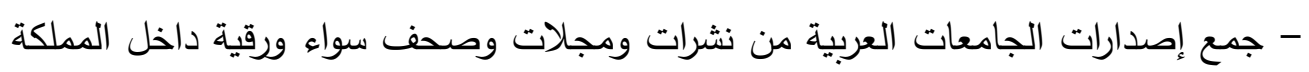

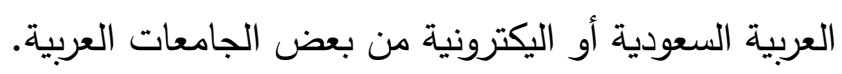




$$
\text { - }
$$

- جوانب التحليل التي تمت في الصورة النهائية للاستمارة الدول واشثتملت على مايلي:

1-السعودية

$$
\text { 2-البحرين }
$$

3-سلطنة عمان

4-الإمارات

5-قطر

6- 6-الأردن

7-مصر

8-الكويت

9-لبنان

الجامعات وإثتملت على الجامعات التالية

1- جامعة المجمعة

r r جامعة الملك سعود

ك- جامعة شقراء

ع- جامعة حائل

0- جامعة الملك فيصل

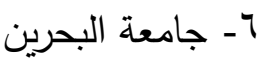

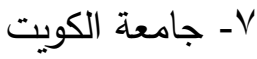

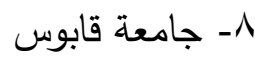

9 - جامعة القاهرة

10-جامعة بيروت العربية

11-جامعة الثارقة

12-جامعة قطر 
د/ عبد الباقي محمد عرفة سالم

13-الجامعة الأردنية

صحف واشتملت على (النشرات والمجلات التالية)

\begin{tabular}{|c|c|c|c|}
\hline عدد الصفحات & نوع الإصدار & الصحيفة & 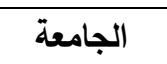 \\
\hline غير محددة من 32- 44صفحة & صحيفة ورقية واليكترونية & الجامعة & الملك سعود \\
\hline غير محددة من 20 إلى 32 صفحة & صحيفة ورقية واليكترونية شهرية & تواصل & 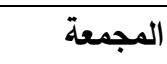 \\
\hline غير محددة من 16 إلى 24 صفحة & صحيفة ورقية واليكترونية شهرية & الإعلام & شقراء \\
\hline غير محددة من 19 إلى 40 صفحة & صحيفة ورقية واليكترونية شهرية & الجامعة & حائل \\
\hline غير محدة من 24-32 صفحة & صحيفة ورقية واليكترونية شهرية & إلثراقهة & الملك فيصل \\
\hline ضفير محدة من 80 إلى 120 & صحيفة ورقية واليكترونية شهرية & أفاق الجامعة & جامعة \\
\hline 24 صفحة & صحيفة $\quad$ ورقية $\quad$ واليكترونية & أفاق & جامعة \\
\hline 16 صفحة & صنوية صحيفة ورقية واليكترونية ربع & المسار & قابوس \\
\hline غير محددة من 40 إلى 52 صفحة & صنوية ورقية واليكترونية ربع & نشرة شئون & جامعة قطر \\
\hline 12 صفحة & شهرية ورقية واليكترونية نصف & أخبار & الثشارقة \\
\hline غير محدد من 12 إلى 40 صفحة & صحيفة ورقية واليكترونية شهرية & أخبار & الألجامعة \\
\hline غير محددة من 4-8 صفحات & صنوية صيفة ورقية واليكترونية ربع & المجتمة البئة & القاهرة \\
\hline 64 صفحة 64 & صنوية ت ورقية واليكترونية ربع & الزميل & بيروت \\
\hline
\end{tabular}

موقع المادة في الصحيفة:

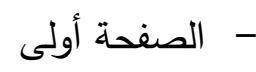

- مفحة داخلية

- - - - - الصفحة الأخيرة 


$$
\text { - - مفحات ملألوان: انقسمت إلى فئتين، هما: }
$$

شكل المادة الصحفية: وقسمت كالتالي:

$$
\text { - }- \text { - }
$$

اتجاهات المادة الصحفية: - الصيز

1-إيجابية نحو المعاقين.

2سلبية نحو المعاقين.

$$
\text { 3-محايدة }
$$

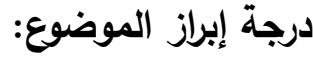

$$
\text { - }
$$

$$
\text { نوع الإعاقة وحددت كالتالي: }
$$

-

- - - معوبات تعلم

$$
\text { - }
$$

-

-

- - اضطرابات تواصل

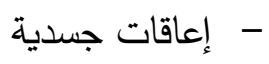

- - اضطرابات سلوكية 
- تشتت انتباه ونشاط زائد - تعدد عوق

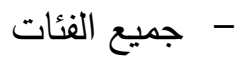
القضايا التي تم تناولها مجال الإعاقة:

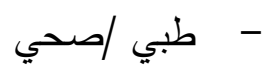

$$
\begin{aligned}
& \text { - تشريع /نظم /حقوق } \\
& \text { - تربوي /تدريس } \\
& \text { - توظيف/ تأهيل } \\
& \text { - } \\
& \text { - نفسي - } \\
& \text { - توعوي/ إعلامي - تعني } \\
& \text { - } \\
& \text { الإصدار } \\
& \text { - } \\
& \text { - شهري } \\
& \text { - فصلي - }
\end{aligned}
$$

محددات الدراسة :

أولا: الحدود المكانية:

اختارت الدراسة عدد من الجامعات العربية تمثل تسع دول عربية أمكن الحصول

منها على عدد من إصدارات الجامعات من صحف ونشرات ومجلات دورية سواء أكانت

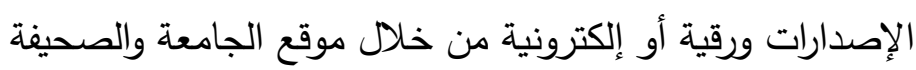

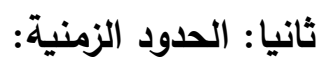

تم اختيار الإصدارات في الفترة من 2011-2014حتى يسهل اختيار الإصدارات

حيث إن عدد من الجامعات أصدرت صحف ونشرات ثم توقفت ولذلك تم مد الفترة الزمنية

$$
\text { لسهولة الحصول على الإعداد المطلوبة إن عند }
$$


حاول الباحث في الدراسة الحالية تطبيق استمارة تحليل المضمون على الصحف الجامعية ( من مجلات ونشرات وصحف) إخبارية واجتماعية تصدر بشكل دوري في

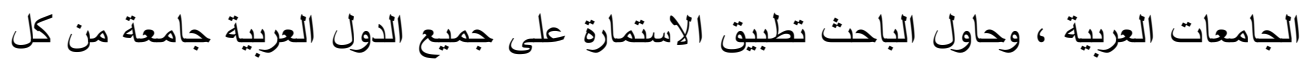

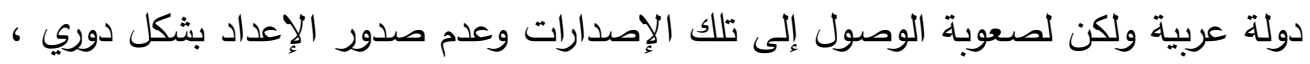

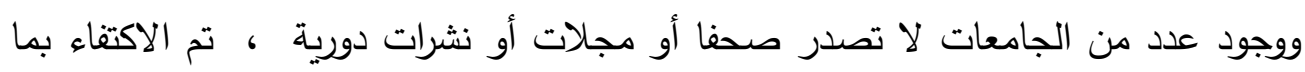

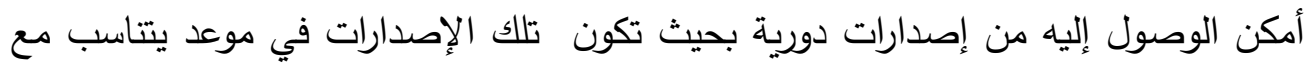

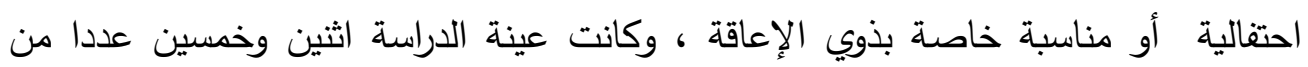

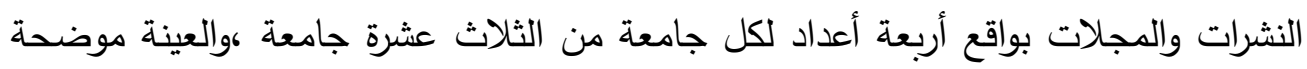
بالجدول كما يلي:

\section{جدول (1)}

أسماء الجامعات عينة الدراسة وأسماء الصحف والنشرات فيكل جامعة ورقم الأعداد

\begin{tabular}{|c|c|c|c|}
\hline المجلة أو النشرة & 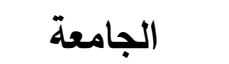 & 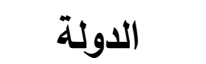 & p \\
\hline صحيفة تواصل الأعداد (23،34،28،) & المجمعة & السعودية & 1 \\
\hline | صحيفة رسالة الجامعة الأعداد & الملك سعود & & \\
\hline$(1135 ، 1140 ، 1157 ، 1160)$ & & & \\
\hline صحيفة الإعلام الأعداد (14،15،14،12) & 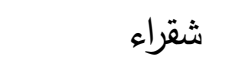 & & \\
\hline رسالة الجامعة الأعداد (3،6،6،3) & 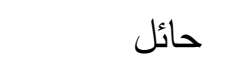 & & \\
\hline مجلة إثراقه الجامعة الأعداد (25، 27،37،38) & 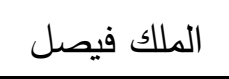 & & \\
\hline مجلة أفاق الجامعة الأعداد (4، 5،8،9) & جامعة البحرين & 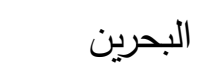 & 2 \\
\hline جريدة أفاق الأعداد (1016،1013،1000،969) & جامعة الكويت & 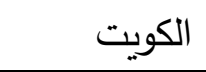 & 3 \\
\hline صحيفة المسار الأعداد(284،281،279،277) & جامعة قابوس & سلطنة عمان & 4 \\
\hline نشرة شئون الطلاب الأعداد (16،16/16،17) & جامعة قطر & قطر & 5 \\
\hline نشرة خدمة المجتمع والبيئة الأعداد (4،3،2،1) & 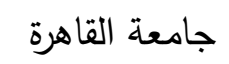 & 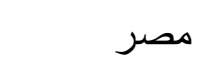 & 6 \\
\hline |صحيفة أخبار الجامعة الأعداد (،9،6،6) & جامعة الثارقة الثار & 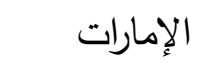 & 7 \\
\hline
\end{tabular}


د/ عبد الباقي محمد عرفة سالم

\begin{tabular}{|c|c|c|c|}
\hline |نشرة أخبار الأردنية الأعداد(484،490،482،412 ) & الجامعة الأردنية & الأردن & 8 \\
\hline مجلة الزميل الأعداد (54، 61 ، 81، & جامعة بيروت & 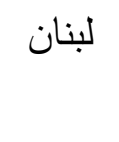 & 9 \\
\hline 13صحيفة، 52 عددا & 13جامعة & & \\
\hline
\end{tabular}

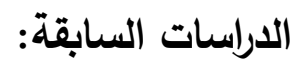

دراسة هندمان، ليتل فيلد، برستون ونيومان (Hindman, et al, 1990)

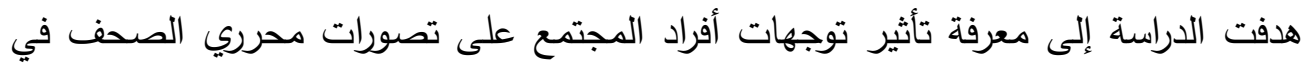

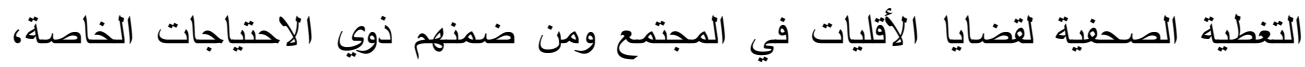
أجريت على شكل مقابلات مع محرري 52 صحيفة من ولاية شمال داكوتا في الولايات

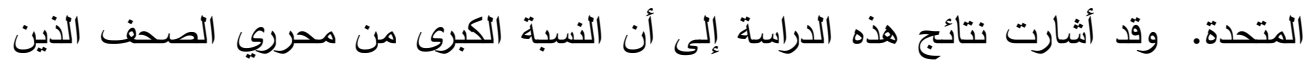

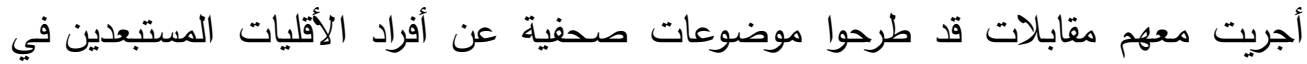

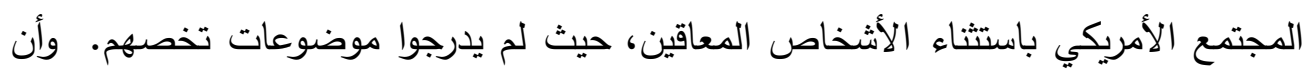
المحرين القلة الذين تحدثا عن الأشخاص المعوقين كانوا في الغالب يركزون على المعاقين

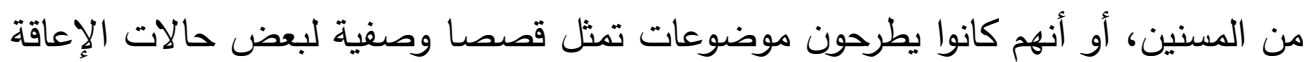
التي تم التغلب فيها على ظروف العجز (1990, Roland,). دراسة هولر Haller)

حيث قامت بدراسة شاملة على وسائل الإعلام الأمريكي بتحليل مضدون 11 صحيفة ومجلة رئيسة، وتحليل مضمون أربع شبكات تلفزة ABC, CBS, NBC, CNN أمريكية خلال عام 1998م. وتم البحث في قواعد الكترونية من خلال أربعة مسميات دالة رئل

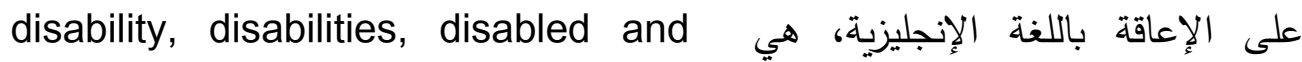
256 وبلغت مجمل القصص الإخبارية في عينة الصحف والمجلات 256 والإنة قصة، وفي عينة المحطات التلفزيونية 35 قصة إخبارية. وبينت نتائج هذه الدراسة على الإسبه الصحف أن معظم الموضوعات كانت عبارة عن أخبار بنسبة 48\%، والتحقيقات بنسبة

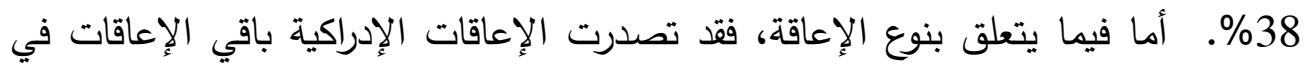


اهتمام الصحافة، تلتها صعوبات التعلم، ثم الإعاقة العقلية، والاضطرابات الوجدانية. كما أشارت نتائج الدراسة إلى أن استخدام كلمة المعاقين handicapped لم لم تعد مستخدمة

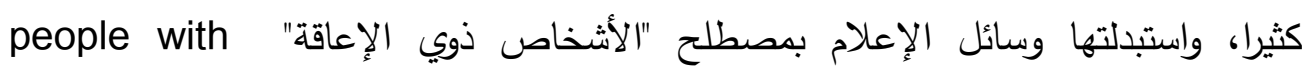
ومن الملفت للنظر أن صحيفة كبرى مثل النيويورك تايمز هي أكثر الصحف لإعل disability

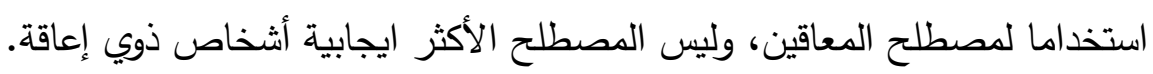
أما التغطية التلفزيونية، فمن الملفت لها محدودية القصص الإخبارية عن المعاقين، حيث وصلت إلى حوالي 35 قصة في الأربع شبكات التلفزة الرئيسة في الولايات المتحدة الإنياتهن

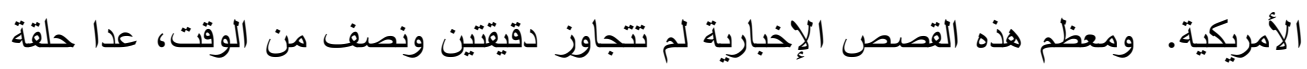

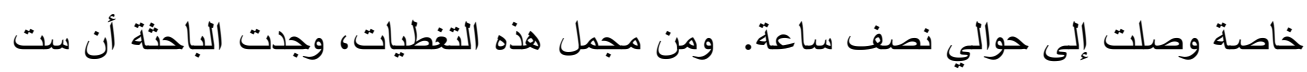
قصص قد استخدمت مصطلح المعاقين، بدلا من استخدام مصطلحات أخرى أكثر إيجابية (Parker, Elliott1996) صحف يومية كبرى إضافة إلى ثلاث مجلات إخبارية أسبوعية في الولايات المتحدة الأمريكية للتعرف على تغطيتها الصحافية لقانون "الأمريكيون والإعاقة" خلال الفترة من 1988 إلى فلى 1993م. وركزت معظم التغطيات لهذا القانون على ثلاث مسائل هي التعديلات البيئية العمرانية (26\%)، ومكافحة التمييز لشرائح المعاقين (22\%)، وإتاحة فرص العمل (18\%). وفيما يتعلق باعتماد هذه الصحف والمجلات على مصادر معلومات عن القانون أو ردود الفعل، أوضحت الدراسة أن 35\% جاءت من مؤسسات وجماعات تمثل ذوي الاحتياجات

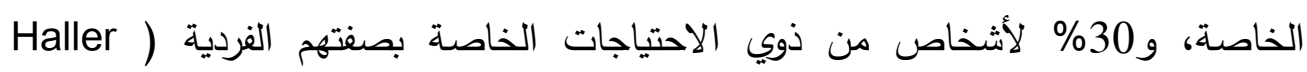
(Beth1993

دراسة صحافية بجامعة جلاسكو بالمملكة المتحدة، أتضح أن من مجموع 562 مادة

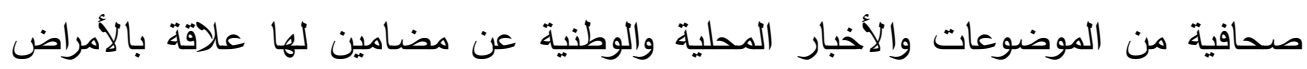
العقلية، تثكل 62\% منها قصصا ذات سمة تربط هذه الفئات بالعنف والجريمة نحو

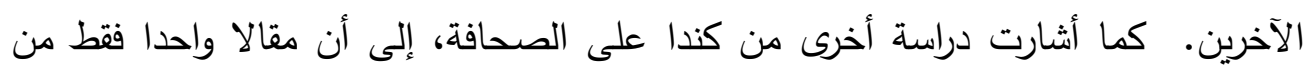

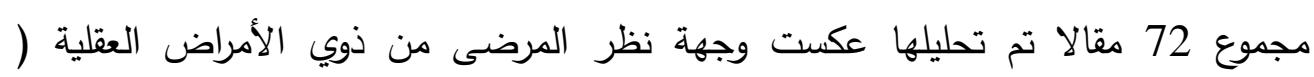
. Edney(2004 
هدفت إلى تحليل مضمون أعداد من جميع الصحف السعودية التي تصدر باللغة العربية

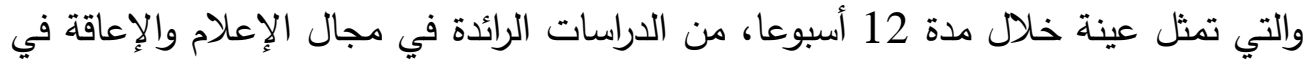
السعودية، حيث أشارت هذه الدراسة لعدد من النتائج الهامة، كان منها: خصصت الصحافة السعودية مساحات مناسبة لطرح قضايا الإعاقة والمعوقين في أعدادها مانها

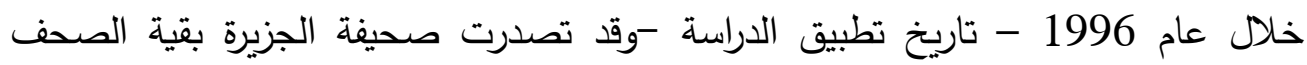
السعودية اليومية في حجم الاهتمام بقضايا الإعاقة، وحلت صحيفة الرياض ثانيا وعكاظ ثالثا في هذه التغطية ثم تلت صحف المدينة والبلاد واليوم والمسائية (التي توقفت فيما بعد) وأخيرا الندوة.

ركزت الصحافة السعودية في تلك الفترة على الجوانب الخبرية والتقارير والتغطيات

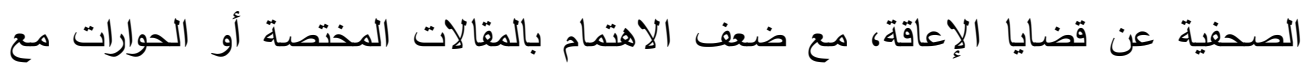
المختصين والتحقيقات الصحفية والتي تعد جميعها مصدر هام للمعلومات وتغيير الاتجاهات. ويبدو أن معظم الأخبار التي تم نشرها عن قضايا الإعاقة تكون مرسلة من هن هندات جهات لها علاقة بالتربية الخاصة ولا تكون باجتهادات شخصية من المؤسسات الصحفية.

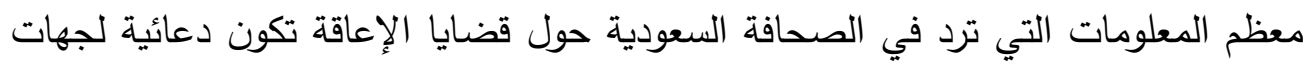

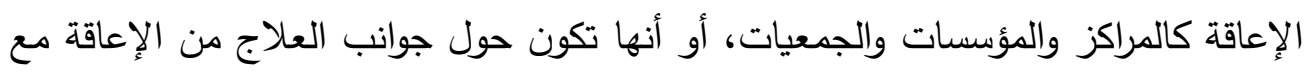

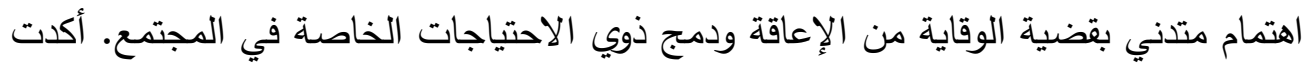
الدراسة على ضعف التواصل بين الجهات المرتبطة بالإعاقة وبين المؤسسات الإعلامية واستثمارها كوسائل جماهيرية داعمة لقضايا الإعاقة. يبدو أن الاهتمام الأكبر لدى العاملين

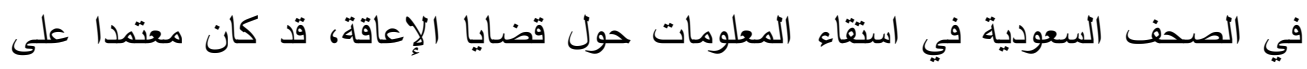

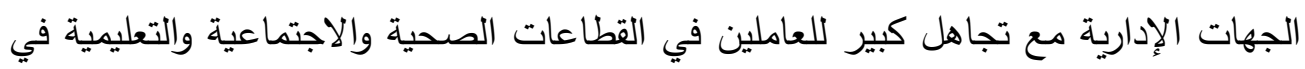
تقديم معلومات توعوية وعلمية تصب في إطار خدمة فكرة قبول المعاقين وتسريع فكرة دمجهم في المجتمع (المقوشي 2000) دراسة هاردن، هادرن، لاين، والزدروف 2001 (Hardin;Hardin;Lynn;Walsdrof وهدفت الدراسة إلى تحليل عدد ونوع الصور المرفقة عن الأثخاص المعاقين في المقالات لاتين، 
د/ عبد الباقي محمد عرفة سالم

والإعلانات الخاصة بمجلة رياضية أمريكية، شملت العينة 36 عددا من أعداد المجلة تتضمن 7092 صورة متنوعة داخل العدد، منها 1527 صورة إعلانية و 5565 صورة مرفقة بموضوعات صحفية. وقد توصلت النتائج على أن ذوي الاحتياجات الخاصة غالبا لا

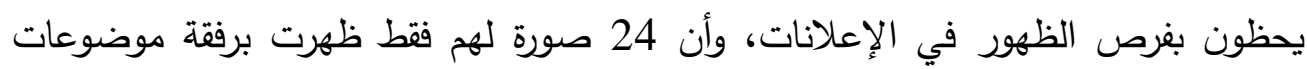

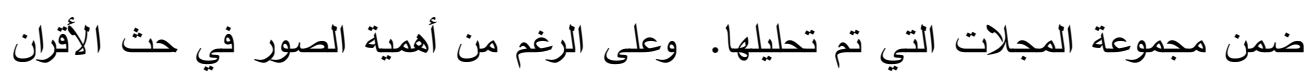

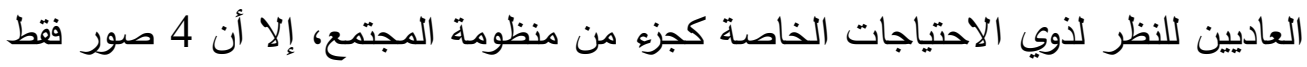
من 24 أظهرتهم كأشخاص فاعلين ويعملون ضمن فريق من الأثخاص العاديين، وبقية

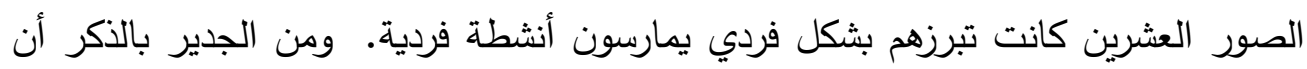

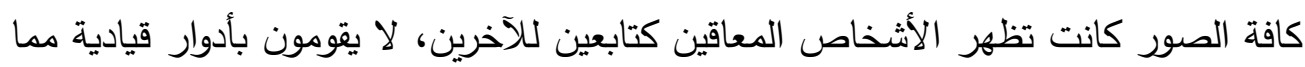
يعمق الإحساس لدى المشاهد بالضعف في إمكانيات الثخص المعاق ومحدودية عطائه.

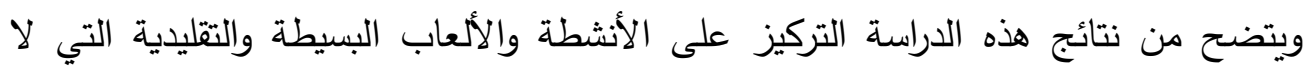

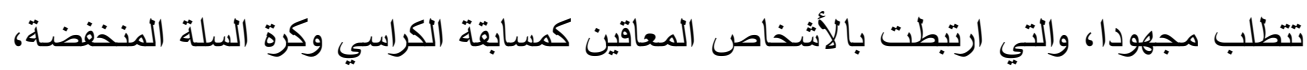
أما الأثطة الصعبة كالمصارعة وكرة القدم والتسلق فلم تظهر الصور أية مشاركات

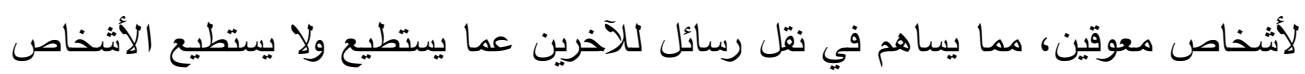

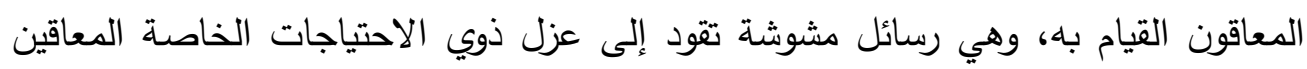
ودفعهم خارج إطار المجتمع(Harden2001). دراسة سحر الخشرمي (2007) هدفت هذه الدراسة إلى تحليل لمحتوى الموضوعات المرتبطة بذوي الاحتياجات الخاصة بشكل عام في الصحافة العربية وعلى وجه الخصوص ما يتعلق بمناسبة اليوم العالمي

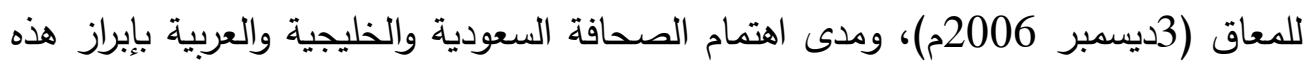
المناسبة كإحدى المناسبات الهامة المتعلقة بالإعاقة. ولتحقيق غرض الدافئم الدراسة، عمدت الباحثة إلى تحليل 15 صحيفة عربية، تمثلت في صحف سعودية من المناطق الرئيسة في المملكة العربية السعودية، 5 صحف خليجية من باقي دول مجلس التعاون الخليجي، 6 صحف عربية من دول الثام وأفريقيا، وصحيفتين عربيتين تصدران من لندن، وذلك على مدى أسبوع دافي دول

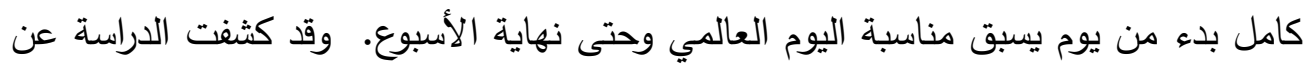


اهتمام عام محدود لدى الصحافة العربية بقضايا الإعاقة حتى في المناسبات الهامة مثل اليوم العالمي للمعاق. كما خرجت الدراسة بما يدل على وجود فجوة بين الإعلاميين والتربويين

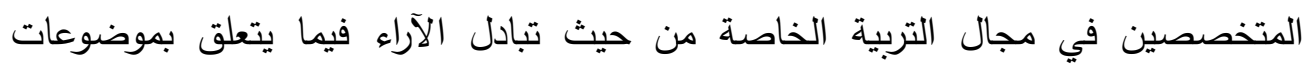
الإعاقة وما ظهر من المسميات السلبية والمصطلحات النمطية عن ذوي الاحتياجات الخاصة في الصحافة العربية. وأوضحت الدراسة محدودية الاهتمام بالمقالة الصحفية في إبراز قضايا

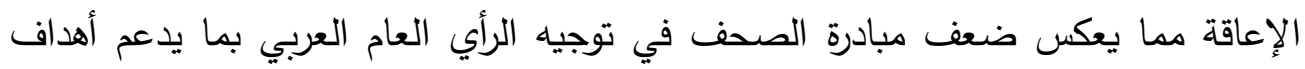

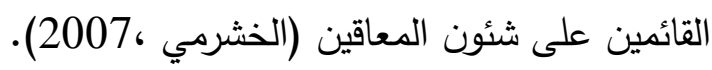
دراسة محمد عبد الرحمن السيد (2007) هدفت الدراسة إلى التعرف على الجهود المبذولة في مجال صحافة الأشخاص

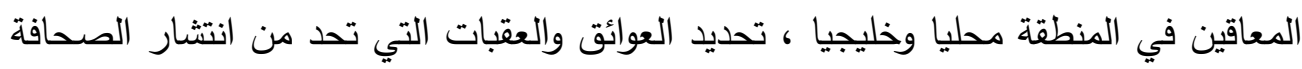
المتخصصة وتحديد أوجه القصور في وسائل الإعلام بثكل عام ، التعرف على نظرة

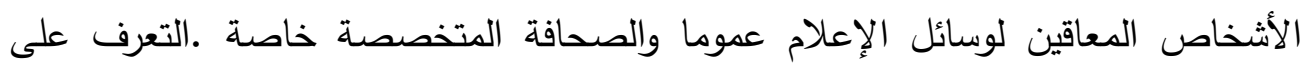
مدى استطاعة الإعلام المتخصص والعام في القيام بمسئولياته تجاه هذه الفئة .وتوصلت الدراسة إلى مجموعة من العقبات التي تحد من انتشار الصحافة المتخصصة منها عدم وجود

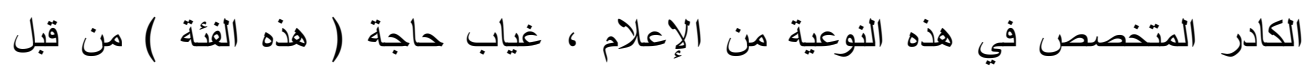
المسؤولين على الصحافة لوجود صحافة متخصصة ، غياب الدعم المالي من الدولة تجاه الصحف والمجلات المتخصصة التي تصدر عن هيئات ومؤسسات ذات علاقة بالإعاقة ، عئه العمل في هذه المطبوعات يعتمد اعتمادا كليا على العمل التطوعي .(السيد 2007) دراسة على شويل القرني (2007) دراسة مسحية عن الصورة والاهتمامات في وسائل الإعلام السعودية وتهدف الدراسة إلى مناقثة العلاقة بين وسائل الإعلام وموضوعات وقضايا ذوي الاحتياجات الخاصة، بما لإماتهات

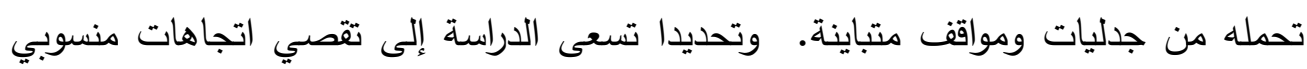

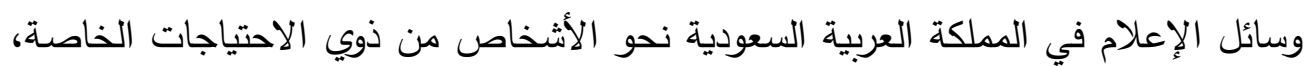
للتعرف على علاقة هذه الاتجاهات بالصورة التي ترسمها وسائل الإعلام عن هذه الفئة. 
واعتمدت الدراسة على المنهج المسحي على عينة من منسوبي وسائل الإعلام المقروء والمسموع والمرئي في المملكة، حيث بلغت العينة 141 فردا، استجابوا لاستبانة البحث التي استخدمت مقياس يوكر لدراسة الاتجاهات نحو ذوي الاحتياجات الخاصة، إلى جانب أسئلة

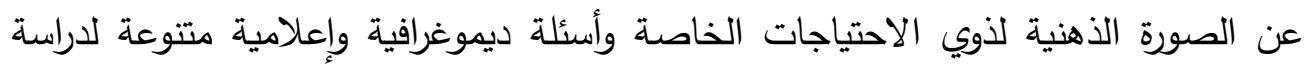
علاقة هذه المتغيرات بصورة المعاقين في وسائل الإعلام السعودية. وأشارت نتائج هذهاته

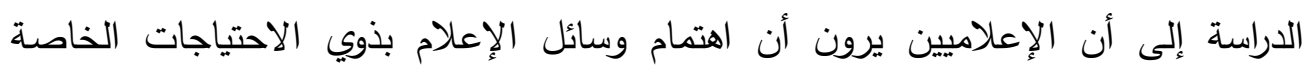

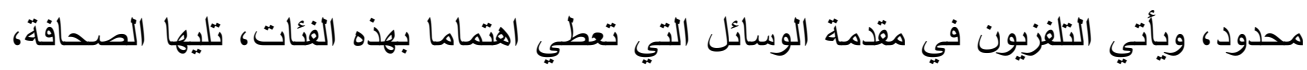

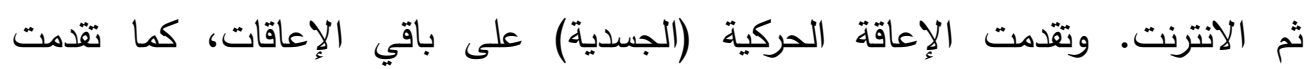
موضوعات الوقاية من الإعاقة على باقي الموضوعات الأخرى في اهتمامات وسائل الإعلام

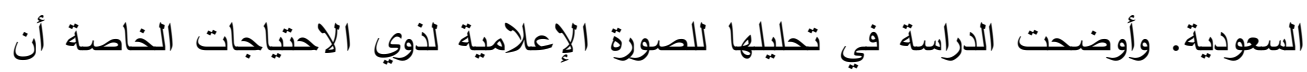

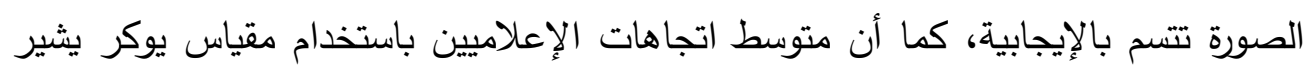
إلى توجهات ايجابية نحو ذوي الاحتياجات الخاصة.

(شويل 2007)

دراسة خالد عبدالله الحلوة (2012) هدفت الدراسة إلى التعرف على المقصود بالإعلام الجديد، والتعرف على الفرق بين وسائل الاتصال الجماهيري ووسائل الاتصال الثخصي، خصائص الإعلام الجديد من منظور (نظرية الوسيلة)، وتوصلت الدراسة إلى أن هناك حاجة لدراسات جديدة تأخذ في الاعتبار

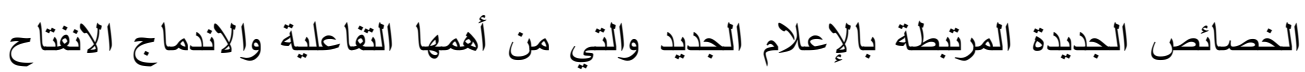

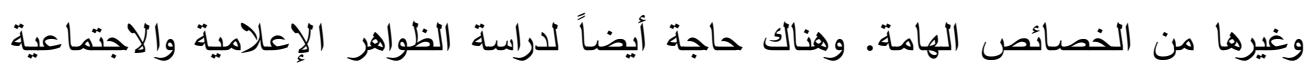
الأساسية التي لا زالت تثغل بال المجتمعات ولم تكن وسائل الاتصال الجماهيري التقليدية

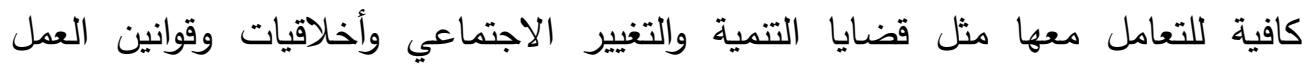
الإعلامي، التي في الواقع تزداد الحاجة إلى دراساتها في الوقت الحاضر أكثر من أي وقت واعت واتِ

$$
\text { مضى (الحلوة 2012) }
$$


تهدف الدراسة إلى أهداف تحليلية ومنها تحديد نوع المضمون في جريدة " أخبار الجامعة " وأنواع الفنون التحريرية خلال فترة الدراسة والتعرف على المصادر التي اعتمدت عليها الجريدة وأنماط الجمهور التي توجهت له و أهداف ميدانية منها رصد دونه دوافع استقبال / عدم استقبال الصحف الجامعية .اختبار فرضيات نظرية الاستقبال على قطاع هام وهو جمهور الجامعة

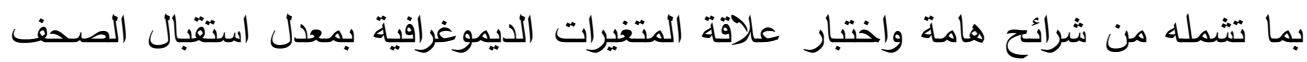

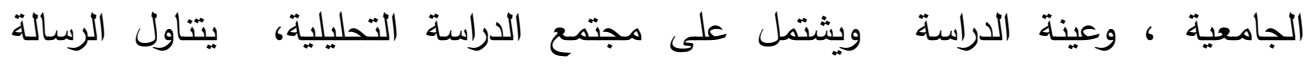
الصحفية Message المقدمة في جريدة "أخبار الجامعة" خلال فترة الدراسة وبلغ حجم العينة

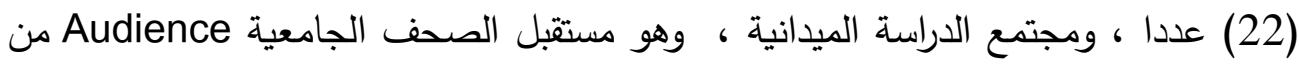

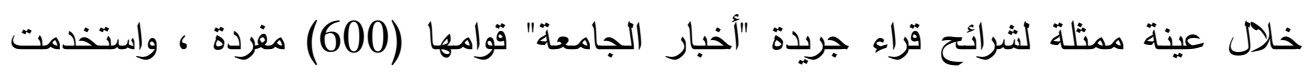

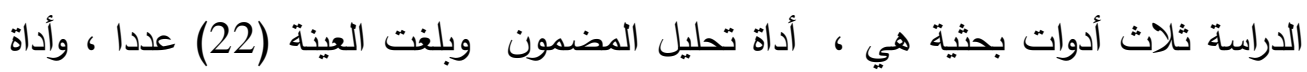
المسح الميداني العينة ، عينة عشوائية قوامها (600) مفردة و مجموعات النقاش المركزة حيث تم إجراء (10) جلسات بحثية. وتوصلت الدراسة إلى النتائج التالية نتائج الدراسة

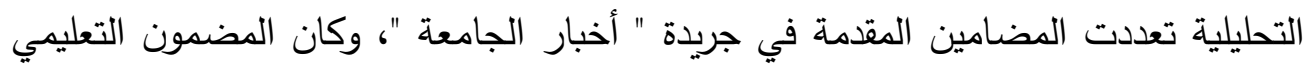
في المركز، توجه مضمون الجريدة لجميع الفئات، واعتمدت الجريدة على مصادر متعددة للمعلومات في مقدمتها الجمهور الجامعي من أساتذة ومسئولين. وتتوعت فئات المواد الإخبارية واحتلت الأخبار البسيطة المركز الأول بنسبة 44.6\%؛ تليها الأخبار المركبة

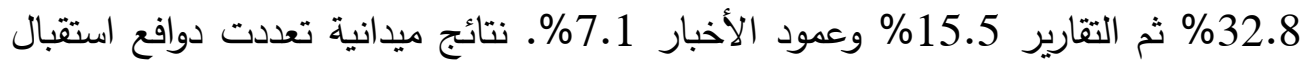

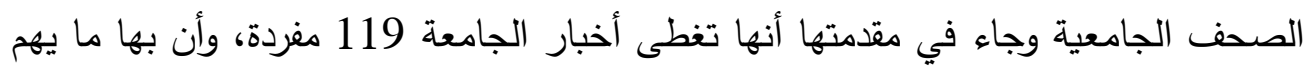
الجمهور الجامعي (105) مفردة، أما دوافع عدم الاستقبال فقد تتوعت ما بين الاكتفاء

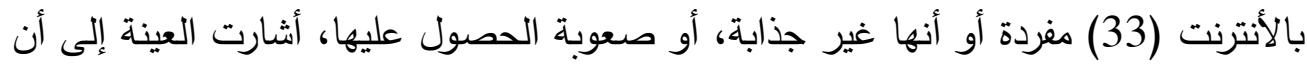

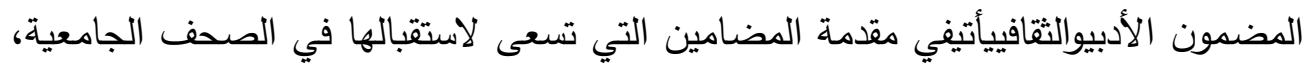

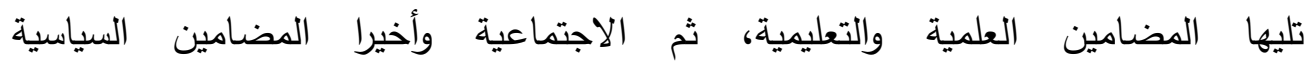
والاقتصادية.(الجمال ، 2008) دراسة سحر فاروق الصادق (2008) 
هدف الدراسة، يسعى البحث للوقوف على رؤية أصحاب الاحتياجات الخاصة لملامح الدور

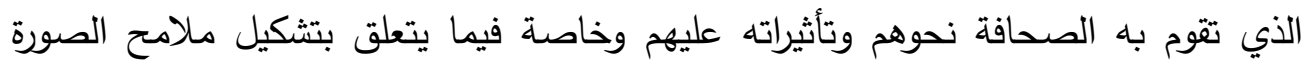

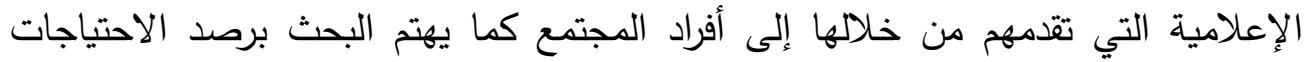
الحقيقية التي ينشدها أصحاب هذه الفئة من وراء علاقتهم بالصحف والتعرف على طبلى طبيعة

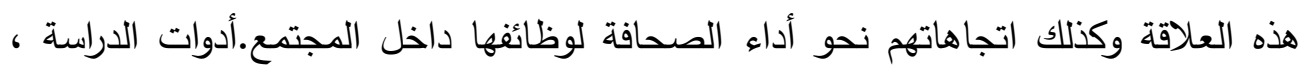

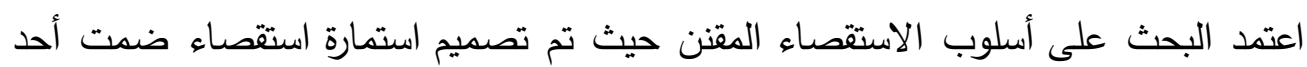

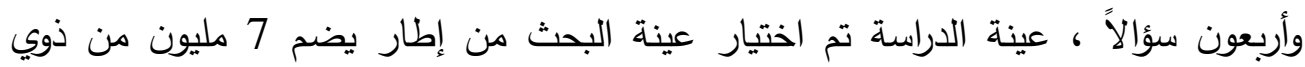

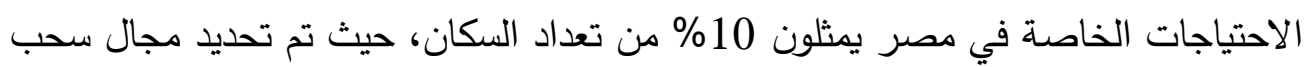
عينة الدراسة من خلال البطولة السادسة لمنتخبات المحافظات بجامعة حلوان، من خلال عينة عشوائية من المشاركين في هذه الدورة، وتوصلت الدراسة إلى كثفت مؤشرات الجداول

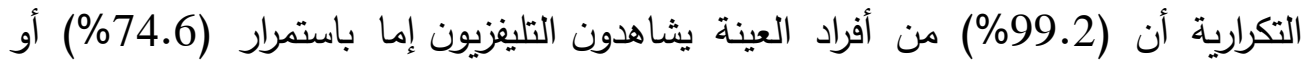
أحيانًا (24.6\%) ، أما الراديو فيستمع إليه (90\%) من (أفراد (أفراد العينة إما بثكل دائم (42.5\%) أو أحيانًا (47.5\%) والنسبة الغالبة (55\%) تقضي أقل من ساعة في الاستماع

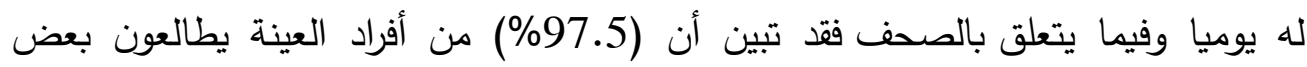

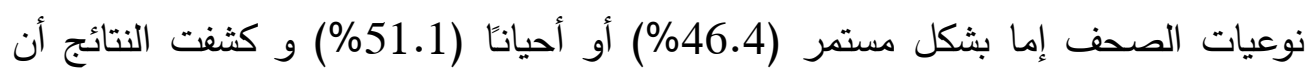
النسبة الأكبر من العينة (55.4\%) ترى أن الصحافة تقدم صورة حقيقية عن ذوي الاحتياجات الخاصة، وإن كانت هذه الصورة لدى نسبة كبيرة منهم (46.1\%) تظهر أحيانًا وليس في جميع الأوقات والمعالجات .(الصادق، 2008) دراسة عمر عبيد حسنة (2012)

تهدف الدراسة إلى التعرف على دور الإعلام والتوعية ودوره في عرض قضايا

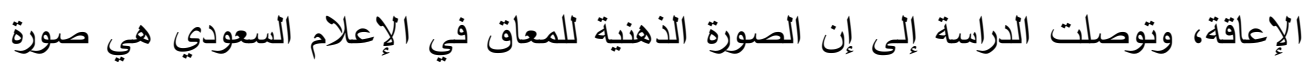
إيجابية، وأوصت الدراسة بما يلي:

ينبغي إجراء بحوث إعلامية مستفيضة، خاصة من خلال إعداد صحيفة استقصاء/استبانة تخطيطاً لبدء إرسال قناة فضائية متخصصة في الإعاقة وقضاياها. 
- ضرورة أن تشمل مفردات العينة مناطق مختلفة من الوطن العربي، باعتبار القناة المقترحة ستتوجه رسائلها الإعلامية لجمهور من كل الأقطار العربية. - مراعاة أنواع الإعاقة في اختيار الأسئلة التي تتضمنها الصحيفة الصنية.

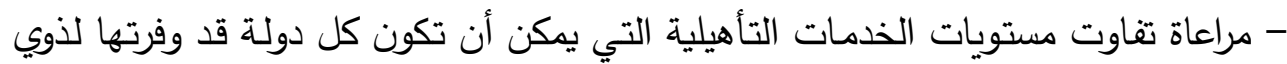
الاحتياجات الخاصة، واستفادوا منها فعلياً. - ضرورة الانتباه إلى أن جمهور الفضائية المتخصصة المقترحة لانئية يقتصر على ذوي الاحتياجات الخاصة فحسب، وإنما يشمل إلى جانبهم: أسرهم، والمتخصصين في مجال ذوري الإنه

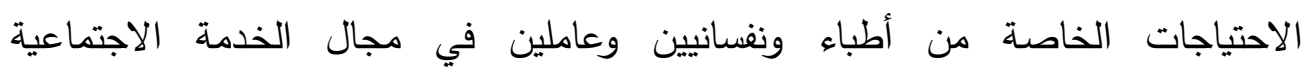

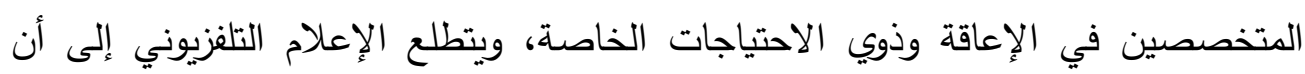

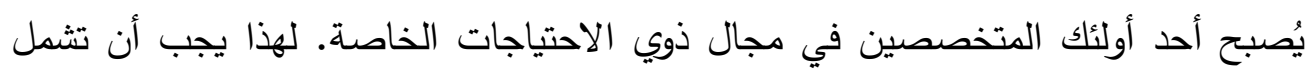
مفردات العينة نماذج من مجتمع المعنيين والمهتمين بالإعاقة وذوي الاحتياجات الخاصة.

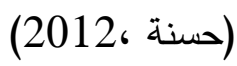

\section{تعليق على الدراسات السابقة}

من خلال العرض السابق للدراسات العربية والأجنبية لاحظت الدراسة أن الإعلام بما

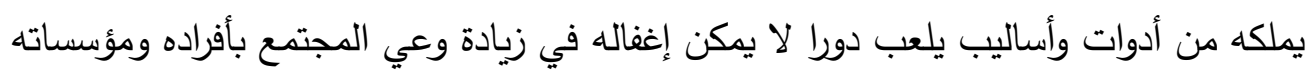

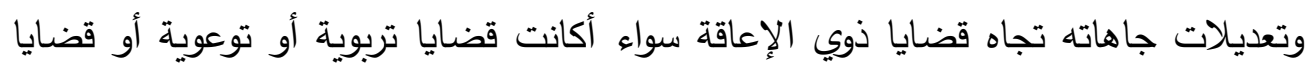
علاجية أو دمج أو غيرها. ويمكن استتتاج وجود اهتمام واضح بقضايا الإعاقة في الصحافة بشكل عام

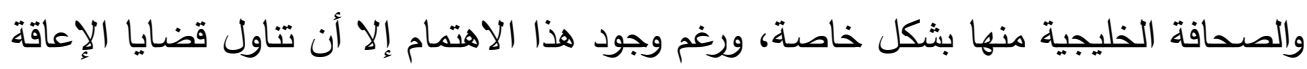
في الصحافة تواجهها العديد من العقبات ومنها عدم الاهتمام بالجوانب الفنية الصحفية في عرض قضايا الإعاقة، معظم الموضوعات المتعلقة بالإعاقة تأتي في الصفحات الدات الداخلية، كثير من القضايا التي يتم تتاولها في الصحافة تأتي من غير المتخصصين، الإعلة هنالك كثير من

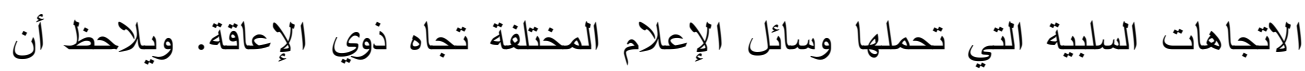
الإعلام الخاص بقضايا الإعاقة يواجه مشكلات من ناحية الكم وهو عدد الموضوعات ولإت وعدد الإعلات

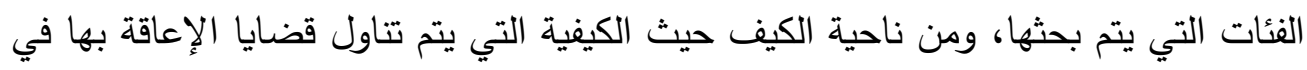


دا دافة الجامعة الباقي محمد عرفة سالم

وسائل الإعلام المختلفة حيث لا يوجد متخصصون بالمعنى الحقيقي في إعلام الإعاقة مثل

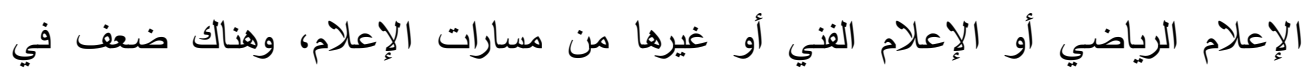

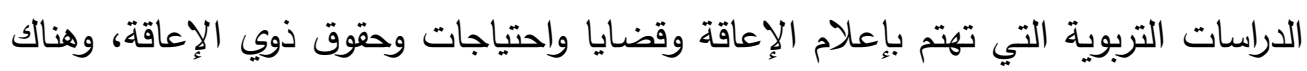
اعتماد كبير على التقارير والأخبار الصحفية بدلا من المقالات والأبحاث.

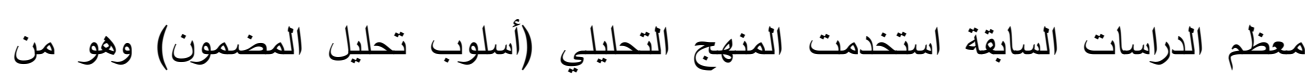
المناهج المناسبة للدراسات الإعلامية بشكل عام.

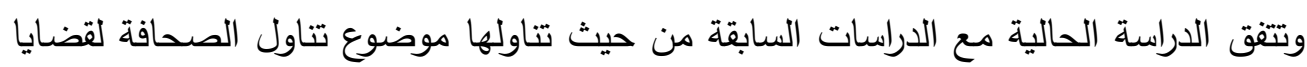
الإعاقة وتختلف من حيث اختيارها لموضوع الصحافة الجامعية الصادرة في الدول العربية حيث لم يتم تحليل مضمون هذه الصحف والمجلات والنشرات في حد علم الباحث في دراسة

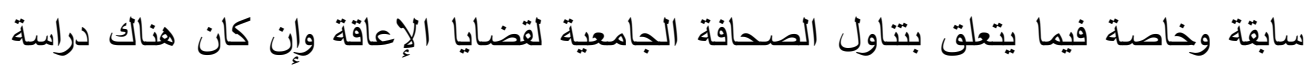
قامت بدراسة العوامل المؤثرة في استقبال الصحف الجامعية دراسة تحليلية مع التطبيق على وإنى جريدة أخبار الجامعة الصادرة عن جامعة الملك عبدا لعزيز (الجمال، 2008)

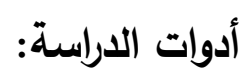

استخدمت الدراسة استمارة تحليل المحتوى حيث إنها من أنسب الأدوات التي يمكن استخدامها

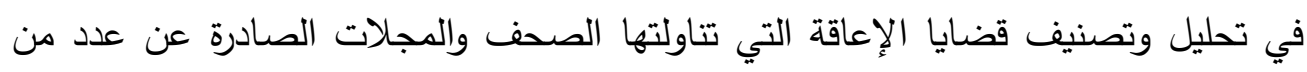
الجامعات العربية وتم الاستفادة من الدراسات السابقة في نفس المجال، في بناء استمارة تحليل المحتوى الحالية، وتم عرض الأداة على عدد من المتخصصين في التربية الخاصة وغيرها من التخصصات حتى خرجت بثكلها النهائي.

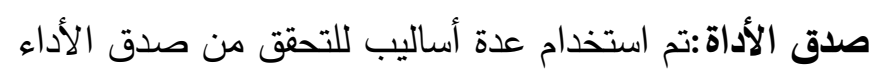

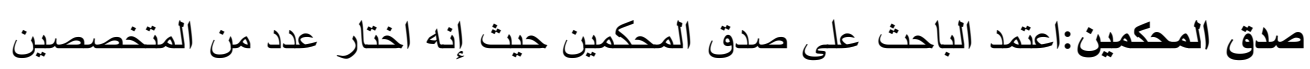
ذوي العلاقة بموضوع الدراسة وكانت نتائج صدق الأداة أكثر من المن البن 88. 


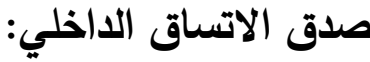

تم تطبيق استمارة تحليل المضمون استطلاعيا على عينة من أساتذة التربية الخاصة بهدف حساب الصدق والثبات، وتم حساب معاملات الارتباط بين عبارات استمارة تحليل المضدون

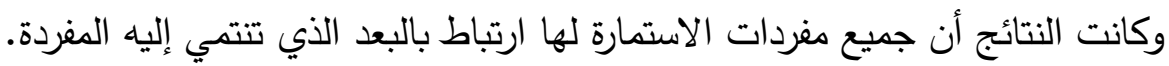

ثبات الأداة: - مات

لحساب ثبات الاستبانة تم استخدام معامل "الفا كرونباخ" لحساب الثبات واستخدم الباحث

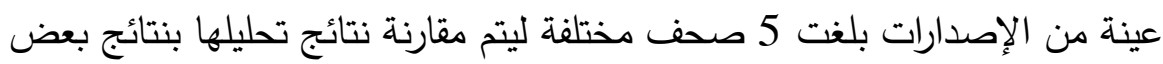

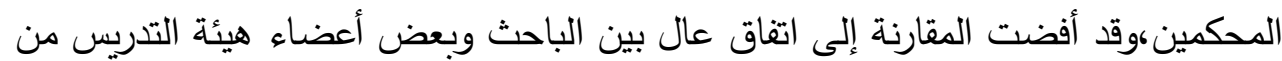
قسم التربية الخاصة، ووصلت النسبة إلى 90\% مما يطمئن إلى نتائج تحليل هذه الدراسة. نتائج الدراسة: ا - للإجابة عن السؤال الأول الخاص بالواقع الحالي للصحافة الجامعية في بعض الدول العربية؟ من خلال بحث الدراسة عن واقع الصحافة الجامعية في الدول العربية توصلت الدراسة إلى عدد من النقاط التالية التي توضح واقع الصحافة الجامعية في الجامعات العربية ومنها: هناك العديد من الجامعات تصدر صحف ونشرات بشكل أسبوعي وجامعات تصدر نشرات وصحف بشكل شهري وجامعات تصدر صحف ونشرات بشكل ربع سنوي وهي كما يلي: - رسالة الجامعة صحيفة أسبوعية تصدر عن جامعة الملك سعود، لنشر آخر الأخبار

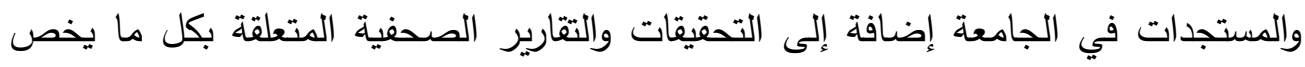
أقسام وإدارات الجامعة ووحداتها الأكاديمية،وترجع قصة نثأة (صحيفة رسالة الجامعة، التي تصدر حالياً عن قسم الإعلام بكلية الآداب في الجامعة، إلى شهر مارس (آذار) 1974، حين عقد مؤتمر ارسالة الجامعة/،، حيث صدرت على هامشه صحيفة يومية حملت اسم المؤتمر، ثم صدرت الصحيفة رسمياً وبصفة دورية عن قسم الإعلام في كلية الآداب

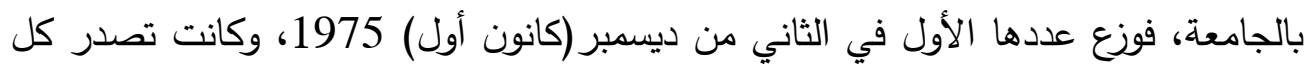

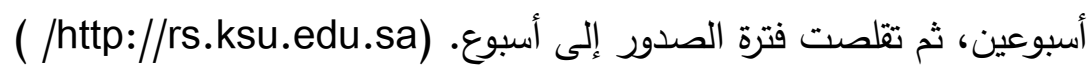


- صحيفة أفاق الكويت تصدر عن جامعة الكويت وهي تصدر أسبوعيا وتأسست عام (http://www.afaq.kuniv.edu) 01978 - ومن الجامعات التي تصدر صحف شهرية: - صحيفة تواصل، صحيفة شهرية تصدر عن العلاقات العامة والإعلام الجامعي بجامعة صندية

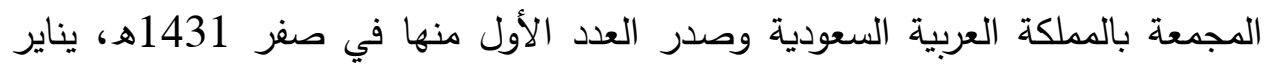
( http://mu.edu.sa/ar). 2010 - صحيفة الأردنية، صحيفة شهرية تصدر عن الجامعة الأردنية المملكة الأردنية الهاشمية (http://www.ju.edu.jo/NewsLetter.aspx?Issue=April\%202014)) - صحيفة الإعلام تصدر عن جامعة شقراء بالمملكة العربية السعودية صدر العدد الأول

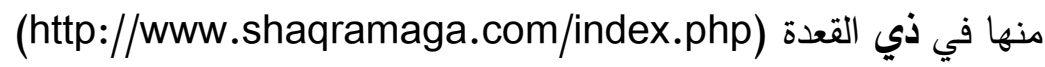
- مجلة أفاق الجامعة تصدر عن جامعة البحرين وهي مجلة شهرية صدر العدد الأول منها

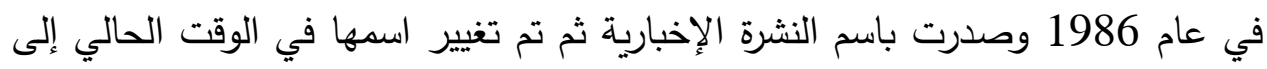

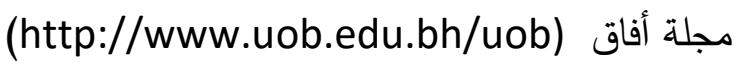
- صحيفة إشراقة الجامعة، صحيفة شهرية، تصدر عن جامعة الملك فيصل (الإحساء)

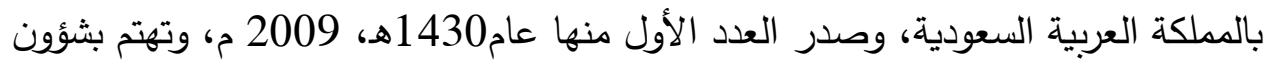

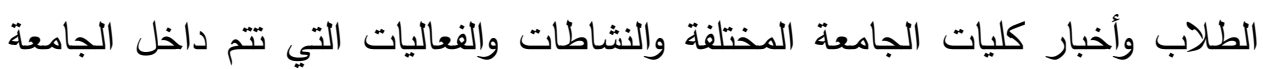
(http://www.kfu.edu.sa/ar/pages/news) - صحيفة الجامعة تصدر عن جامعة حائل بالمملكة العربية السعودية وهي صحيفة شهرية

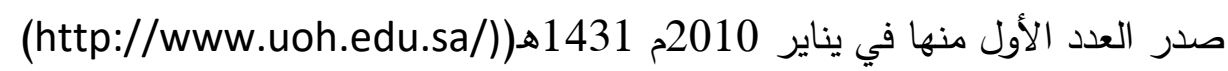
- صحيفة المسار تصدر عنجامعة السلطان قابوس بسلطنة عمان وهي نشرة إعلامية تصدر عن دائرة العلاقات العامة والإعلام وهي صحيفة شهرية(/http://www.squ.edu.om ومن الجامعات التي تصدر صحف فصلية: - مجلة الزميل جامعة بيروت العربية لبنان وهي فصلية تصدر أربعة أعداد في العام وهي

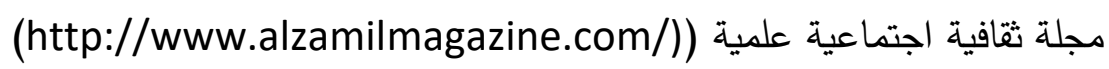
- جامعة القاهرة وتصدر نشرة ربع سنوية بعنوان البيئة والمجتمع وصدر العدد الأول منها في يناير 2010م (http://cu.edu.eg/ar/Journal) 
- نشرة شؤون الطلاب، جامعة قطر نشرة فصلية، صدر العدد الأول منها في أكتوبر 2009،

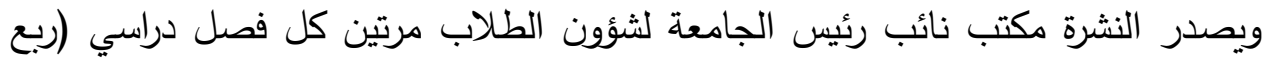

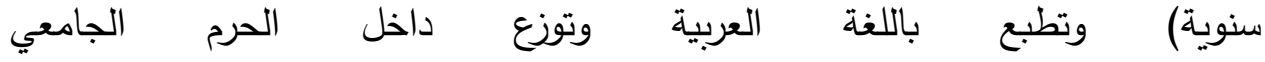

(http://www.qu.edu.qa/ar/students/sa)

- أخبار الجامعة، نشرة إخبارية تصدر عن قسم العلاقات العامة بكلية الاتصال جامعة

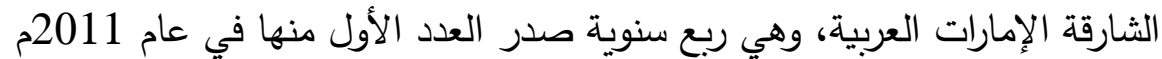

2-للإجابة عن السؤال الثاني الخاص بأكثر الصحف الجامعية العربية اهتماما بقضايا

الإعاقة؟

$$
\text { جدول رقم (2) }
$$

متوسط تكرار المادة الصحفية في صحف الجامعات المختلفة وفق عينة الدراسة

\begin{tabular}{|c|c|c|c|c|}
\hline |النسبة المئوية & 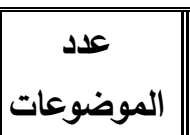 & الدولة & الجامعة & اسم الصحيفة \\
\hline$(\% 20.5)$ & 25 & السعودية & جامعة الملك سعود & رسالة الجامعة \\
\hline$(\% 12)$ & 15 & الأردن & الجامعة الأردنية & أخبار الأردنية \\
\hline$(\% 11.2)$ & 12 & | ل السعودية & جامعة حائل & صحيفة الجامعة \\
\hline$(\% 10)$ & 11 & السعودية & جامعة شقراء & مجلة الإعلام \\
\hline$(\% 3)$ & 4 & 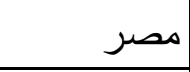 & جامعة القاهرة & نشرة خدمة المجتمع والبيئة \\
\hline$(\% 5)$ & 6 & السعودية & جامعة الملك فيصل & صحيفة إشراقة الجامعة \\
\hline$(\% 5)$ & 6 & البحرين & جامعة البحرين & مجلة أفاق \\
\hline$(\% .8)$ & 1 & الإمارات & جامعة الثارقة & أخبار الجامعة \\
\hline$(\% 9)$ & 10 & الكويت & جامعة الكويت & مجلة أفاق \\
\hline$(\% 6)$ & 7 & قطر & جامعة قطر & نشرة شؤون الطلاب \\
\hline$(\% 8)$ & 10 & 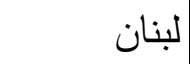 & جامعة بيروت & صحيفة الزميل \\
\hline$(\% 5)$ & 6 & سلطنة عمان & جامعة قابوس & مجلة المسار \\
\hline$(\% 3)$ & 5 & السعودية & جامعة المجمعة & مجلة تواصل \\
\hline$\% 100$ & 122 & & & إجمالي الموضوعات \\
\hline
\end{tabular}


وللإجابة على السؤال السابق وهو ما هي أكثر الصحف الجامعية العربية اهتماما بقضايا الإعاقة ومن خلال الجدول رقم(2) يمكن ملاحظة أن أكثر الصحف الجامعية اهتماما

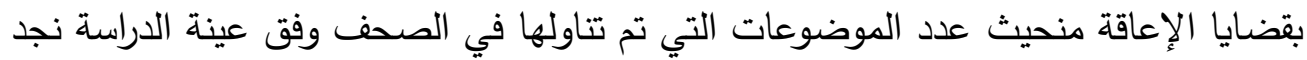
صحيفة رسالة الجامعة تتصدر الصحف الجامعية بعدد موضوعات (25) موضوعا بنسبة

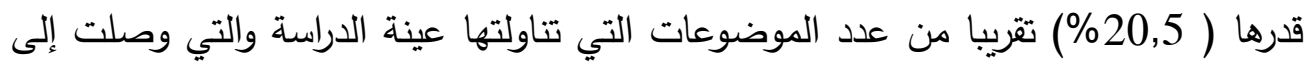

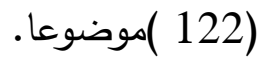

وتأتي صحيفة أخبار الأردنية في المرتبة الثانية من حيث عدد الموضوعات التي تتاولتها الصحيفة وبلغت 15 موضوعا بنسبة (12\%) من عدد الموضوعات التي تتاولتها الدراسة التانة وتأتي صحيفة أخبار الجامعة الصادرة عن جامعة الثارقة في مؤخرة الصحف من من حيث الثيث

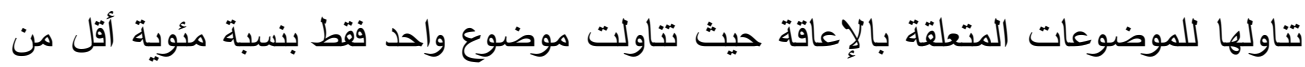

$$
\text { (8) وفق لإحصائيات الدراسة. }
$$

r- وللإجابة عن السؤال الثالثالخاص بأبرز القضايا الخاصة بالإعاقة في الصحافة الجامعية

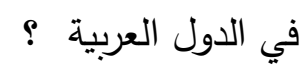

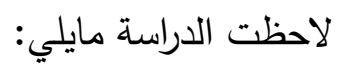

جدول رقم (3) (3)

\begin{tabular}{|c|c|c|}
\hline النسبة المئوية \% & عدد الموضوعات & القضايا \\
\hline $29.5 \%$ & 36 & طبية وصحية \\
\hline $5 \%$ & 7 & حقوق وتشريعات \\
\hline $18 \%$ & 22 & تربوية وتعليمية \\
\hline $5 \%$ & 7 & تأهيلية \\
\hline $2 \%$ & 2 & اجتماعية \\
\hline $4 \%$ & 6 & نفسية \\
\hline $34.5 \%$ & 42 & توعية وإعلام \\
\hline 100 & 122 & المجموع \\
\hline
\end{tabular}

توزيع القضايا الخاصة بالإعاقة في الصحافة الجامعية في الدول العربية 
ومن خلال الجدول السابق يمكن ملاحظة أن القضايا الخاصة بجانب التوعية والإعلام يأتي في مقدمة القضايا التي اهتمت بها الصحافة الجامعية حيث حصلت على نسبة (34.5\%) حيث مثلت الموضوعات المتعلقة بالتوعية والإعلام حوالي 42 موضوعاوتلتها القضايا المتعلقة بالجانب الصحي والطبي بنسبة مئوية( 29.5\% )ثم القضايا المتعلقة بالجانب التربوي والتعليمي بنسبة( 18\%)وتتقق نتيجة الدراسة مع أهداف كثير من الصحف الجامعية حيث تهدف لنشر أخبار الأنثطة والفعاليات المختلفة داخل الجامعة وإعلام مجتمع الجامعة التها والمجتمع الخارجي بتلك الأنثطة المتعلقة بقضايا وأخبار ذوي الإعاقة وتختلف نتيجة الدراسة

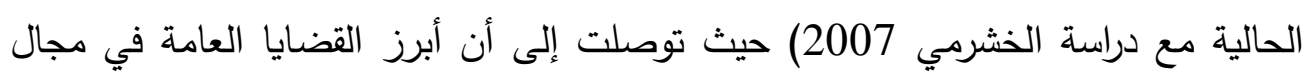

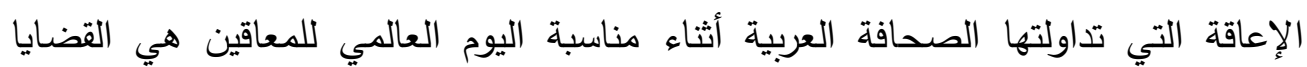
الاجتماعية (21\%)، وإن اتفتت الدراسة الحالية مع دراسة الخشرمي في حصول القضايا

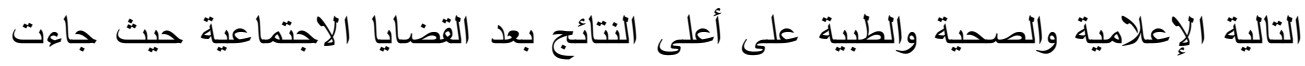
قضية الإعلام والتوعية بقضايا الإعاقة(18\%) ثم القضايا الصحية (14\%) ، ويمكن تفسير ذلك في اهتمام الصحافة الجامعية بنشر قضايا وموضوعات ذوي الإعاقة بغرض توعية الطلاب والمجتمع بقضايا هذه الفئة ، وجاءت في المرتبة الثانية القضايا الصحية والطبية وذلك لاهتمام كثير من إصدارات الجامعات بتوضيح دور المتخصصين من الأساتذة واءت والطلاب وكليات الطب في الجامعات المختلفة في خدمة هذه الفئة من الناحية الصحية والطبية ، من خلال زيارة جمعيات الإعاقة والقيام بحملات علاجية ووقائية .

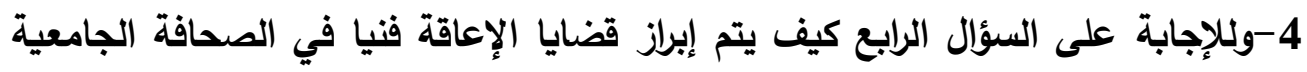

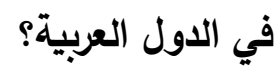


جدول (4)

الثكل الفني لتوضيح المادة الصحفية الخاصة بموضوعات الإعاقة

في الصحف لجامعية العربية

\begin{tabular}{|c|c|c|}
\hline النسبة المئوية \% & التكرار & شكل المادة \\
\hline$\% 26.5$ & 32 & خبر \\
\hline$\% 38.5$ & 47 & تقرير \\
\hline$\% 10.6$ & 13 & تحقيق \\
\hline$\% 16$ & 20 & مقال \\
\hline$\% 8,4$ & 10 & إعلان \\
\hline$\% 100$ & 122 & المجموع \\
\hline
\end{tabular}

ومن خلال الجدول السابق لاحظ الباحث أن أبرز الأشكال الفنية في توضيح المادة الصحفية المتعلقة بالإعاقة في الصحافية الجامعية موضوع الدراسة كانت التقارير بنسبة (38.5\% ) ثم الأخبار بنسبة( 26.5\% )ويلاحظ الباحث وجود اتساق في طبيعة الصحافة

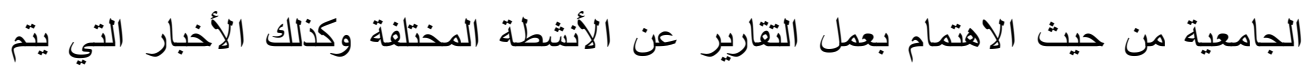
الاعتماد عليها في إيضاح الأنشطة والأعمال الطلابية المختلفة وتتفق الدراسة الحالية مع الدئية دراسة سحر الخشرمي 2007 ودراسة صالح غريب (2007) والتي جاءت بعنوان دور الصحافة تجاه ذوي الاحتياجات الخاصة والتي أكد فيها أن دور الصحافة في تتاول قضايا الإعاقة ما زال منقوصا ولا يخرج عن الجانب الخبري وتتقق كذلك مع دراسة المقوشي

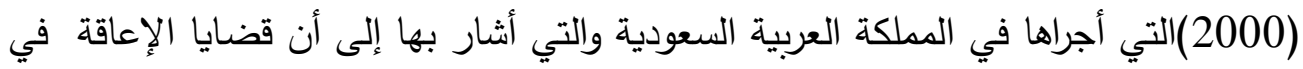
الصحف السعودية تأتي على شكل الخبر والتقرير، وتبتعد كثيرا عن التحقيق والمقالة الصحفية ومن المعلوم أن التحقيق والمقالة من أفضل الأساليب الفنية في إبراز وتوضئحيح

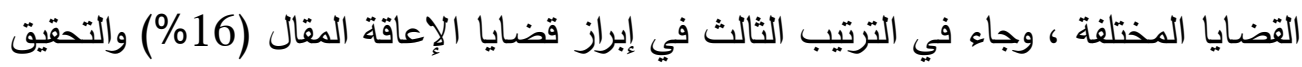
ب( 10.6\% )وفي الترتيب الأخير الإعلان بنسبة( 8.5\% )وهذا يؤكد على حاجة الصحافة 
دا دافة الجامعة الباقي محمد عرفة سالم

الجامعية على تفعيل أشكال إبراز المادة الصحفية المتعلقة بالإعاقة ، وتقسر الدراسة هذا الضعف في إبراز قضايا الإعاقة بسبب أن كثير من العاملين في هذه الصحف من الطلاب

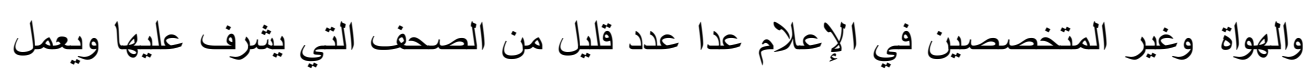

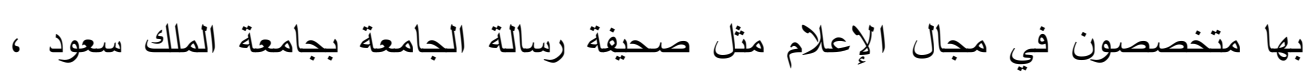

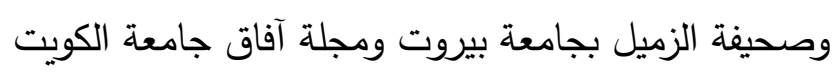

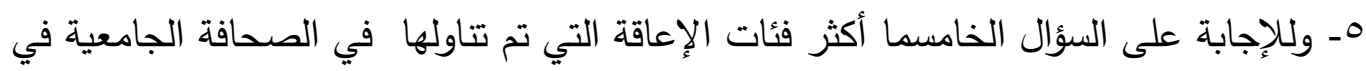

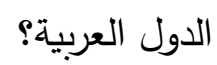

جدول رقم (5)

توزيع الموضوعات الصحفية حسب نوع الإعاقة في الصحافة الجامعية

\begin{tabular}{|c|c|c|}
\hline النسبة المئوية \% & الت التكرار & توزيع الإعاقة \\
\hline$\% 36$ & 45 & الإعاقة الجسمية والصحية \\
\hline$\% 9$ & 11 & الإعاقة البصرية \\
\hline$\% 3$ & 4 & الإعاقة العقلية \\
\hline$\% 9$ & 11 & الإعاقة السمعية والصم \\
\hline$\% 4.5$ & 6 & اضطرابات النطق والكلام \\
\hline$\% 1$ & 2 & صعوبات التعلم \\
\hline$\% 1$ & 2 & الاضطرابات السلوكية التوحد \\
\hline$\% 1$ & 2 & تعدد العوق \\
\hline$\% 32$ & 37 & جميع الفئات (بشكل عام) \\
\hline$\% 100$ & 122 & المجموع \\
\hline
\end{tabular}


ومن خلال نتائج الدراسة وجد أن الصحافة الجامعية الصادرة في الجامعات العربية موضع الدراسة قامت بتتاول موضوعات تتعلق بكل فئات الإعاقة بمختلف أثكالها من عقلية

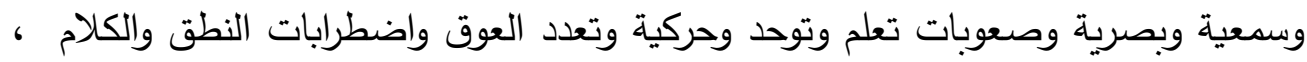

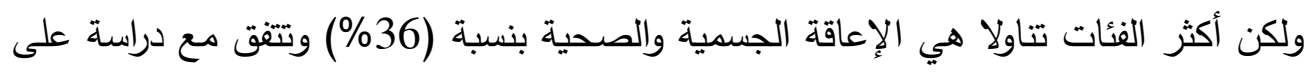
شويل القرني ( 2007) ثم تلتها موضوعات تتحدث عن الإعاقة بثكل عام بنسبة (32\%) ثمجاء في الترتيب الثالث الإعاقة البصرية بنسبة (9\%) والإعاقة السمعية بنفس النسبة وأقل فئات الإعاقة تناولا في المادة الصحفية الجامعية التوحد وصعوبات التعلم وتعدد العوق بنسبة الإبه ( 1\% ) وتختلف الدراسة الحالية عن دراسة سحر الخشرمي (2007) التي تتاولت الصحافة العربية والتي جاءت أكثر المواد الصحفية اهتماما بالإعاقة بثكل عام في الترتيب الأول بنسبة( 58\% ) وكانت في هذه الدراسة في الترتيب الثاني بعد الإعاقات الصحية والجسمية وتختلف الدراسة الحالية عن دراسة الخشرمي في تتاول الدراسة الحالية لجميع فئات الإعاقة لدابة وهذا لم يحدث في دراسة الخشرمي حيث لم يرد حديث عن تعدد العوق والاضطرابات السلوكية وصعوبات التعلم وفق ما توصلت إلية نتائج الخشرميو تتفق الدراسة الحالية عن ئن دراسة يوشيدا وآخرون (Yoshida et al 1988)للصحافة الأمريكية أكدت على اهتمام الصحف الغربية بالإعاقة العقلية والإعاقات الجسدية والاضطرابات السلوكية، حيث يحتلان غالبا أهمية خاصة في الصحف الغربية، مع تجاهل كبير لبعض الفئات مثل حالات

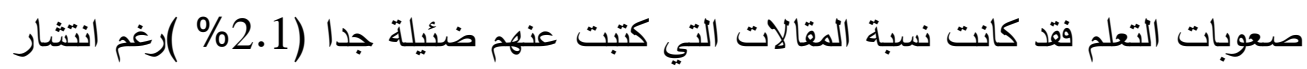
هذه الفئة بين طلاب المدارس العادية. كما أن المعاقين بصريا وسمعيا احتلت مقالاتهم مرتبة ضعيفة جدا حيث بلغت نسبة المقالات (1.1\% )و الأشخاص من ذوي الإعاقات المزدوجة

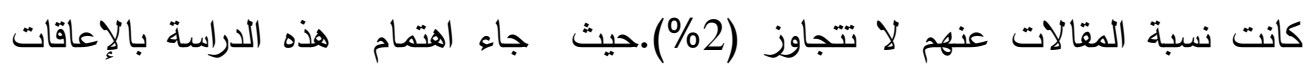
السمعية والبصرية ( الحسية ) وصعوبات التعلم واضطرابات النطق والكلام بنسبة لا تتجاوز

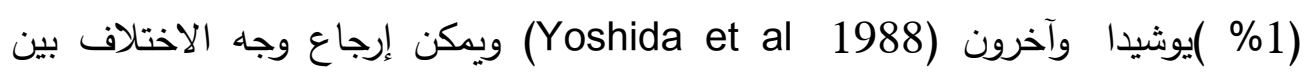
الدراسة الحالية والدراستين السابقتين إلى أن الصحافة الجامعية تعتبر صحافة متخصصة الهصن في بعض الصحف حيث يتوفر بها المتخصصون في مجال التربية الخاصة وفي كثير من

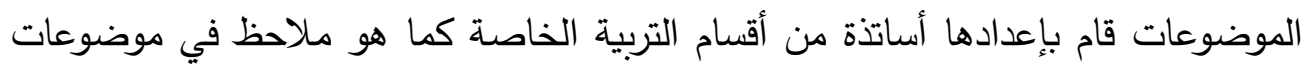


رسالة الجامعة في جامعة الملك سعود وصحيفة الجامعة الأردنية حيث كانت معظم الحوارات والتحقيقات والمقالات مع متخصصين في مجال التربية الخاصة . 6-ولإجابة على السؤال السادس ما الكيفية التي تناولت بها الصحافة الجامعية للقضايا المتعلقة بالإعاقة؟ وتم تقسيم كيفية تناول الموضوعات وفق ما يلي: الألوان المستخدمة موقع المادة في الصحيفة الرسومات والصور التوضيحية

الجدول رقم (6) يوضح استخدام الألوان

\begin{tabular}{|c|c|c|}
\hline النسبة المئوية \% & التكرار & الألوان \\
\hline$\% 86$ & 105 & ملون \\
\hline$\% 14$ & 17 & غير ملون \\
\hline$\% 100$ & 122 & المجموع \\
\hline
\end{tabular}

استخدام الألوان في تتاول الموضوعات يزيد من الانتباه والاهتمام بالإطلاع على الموضوع ومن خلال الجدول السابق يمكن ملاحظة أن (86\%) من الموضوعات التي تم تتاولها في الصحافة الجامعية استخدمت ألوان في عرض الموضوعات ويحسب ذلك ملك للصحافة الجامعية وتختلف هذه النتيجة عن دراسة الخشرميالتي توصلت إلى أن( 81\% من الصحافة العربية لم تستخدم ألوان في تتاول موضوعات ذوي الإعاقة ، ويمكن تقسير ذلك لك

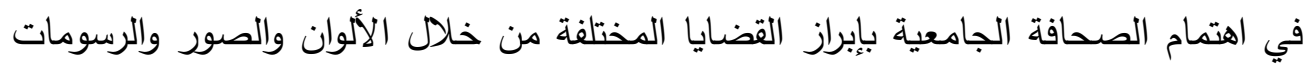

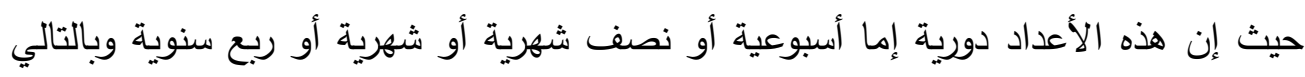

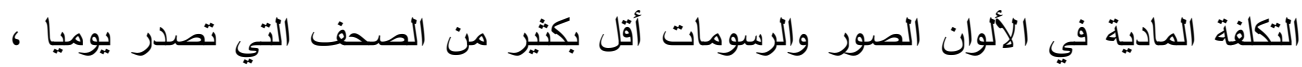

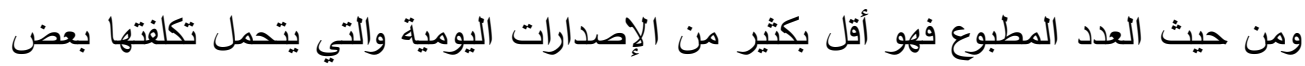

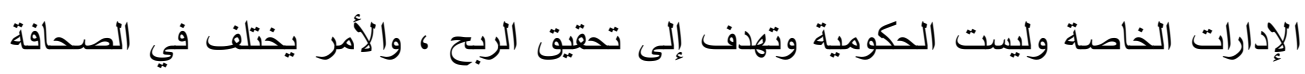
الجامعية المدعومة من الجامعات المختلفة . الجدول رقم (7) يوضح موقع المادة في الصحافة الجامعية 
د/ عبد الباقي محمد عرفة سالم

\begin{tabular}{|c|c|c|}
\hline النسبة المئوية & التكرار & موقع المادة \\
\hline$\% 1$ & 2 & الصفحة الأولى \\
\hline$\% 05$ & 1 & الصفحة الأخيرة \\
\hline$\% 98.5$ & 120 & صفحة داخلية \\
\hline$\% 100$ & 122 & المجموع \\
\hline
\end{tabular}

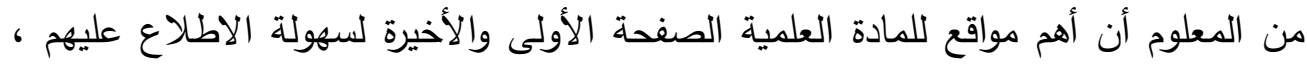
ومن خلال الجدول السابق يلاحظ عدم اهتمام الصحف الجامعية بإبراز الموضوعات التي لماده

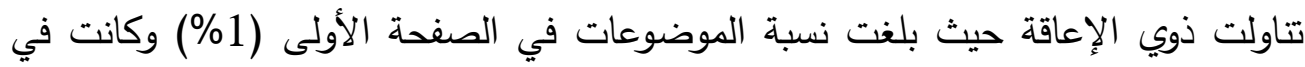
مجلة تواصل لجامعة المجمعة وفي الصفحة الأخيرة 05\% مما يدلل على ضعف الاعلى الاهتمام بموضوعات الإعاقة من الناحية الكيفية وتتفق الدراسة مع دراسة سحر الخشرمي حيث إن الن النيرة (98.5 )من الموضوعات بالصفحات الداخلية وهذا دليل على عدم الاهتمام بقضايا وموضوعات الإعاقة ، ويمكن تفسير ذلك بقلة المتخصصين من ناحية ومن ناحية أخرى

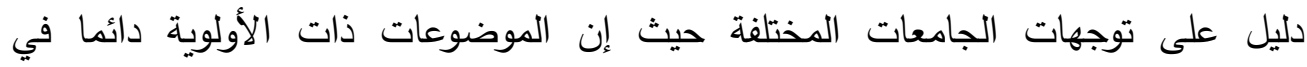
الصفحات الأولى والأخيرة .

$$
\text { الجدول رقم (8) يوضح استخدام الصور }
$$

رب صورة خير من ألف كلمة مثل يوضح أهمية استخدام الصور والرسومات وتأثيرها

\begin{tabular}{|c|c|c|}
\hline النسبة المئوية & التكرار & موقع المادة \\
\hline$\% 61$ & 75 & تم استخدام صور \\
\hline$\% 39$ & 47 & لم يتم استخدام صور \\
\hline$\% 100$ & 122 & المجموع \\
\hline
\end{tabular}

في لفت الانتباه وتوضيح الحقائق ومن خلال الجدول السابق يلاحظ أن الصحافة

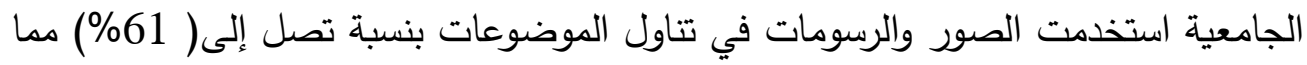

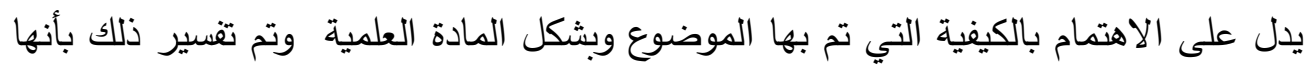
إصدارات دورية وليست يومية وبالتالي هناك اهتمام بإخراج وشكل الموضوعات المختلفة من بن لإنيات 
دافل عبد الباقي محمد عرفة سالم

حيث إثارة الانتباه والجاذبية ، وتختلف الدراسة الحالية عن دراسة الخشرمي حيث إن نسبة استخدام الصور في الصحافة العربية في تتاولها لقضايا الإعاقة (42\% )

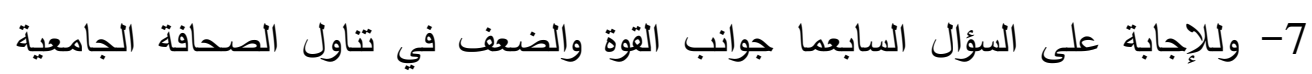
لقضايا الإعاقة؟ من خلال التحليل السابق يمكن ملاحظة جوانب القوة فيما يلي: اهتمام الصحف الجامعية بمختلف فئات الإعاقة حيث تحدثت عن الإعاقات الجسمية والحسية واهتمت بفئات تعدد العوق، وهذا يدل على جانب قوة في سياسة الصحف الجامعية. ومن جوانب القوة الاهتمام بعدد كبير من قضايا الإعاقة بثكل عام مثل التعليمية والتوعوية

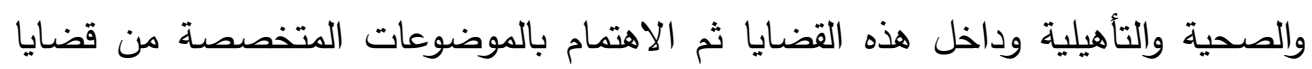
الامج والحقوق والتشريع والتأهيل والتوعية والتدريب والتعليم وغيرها. من مظاهر القوة في الصحافة الجامعية: 1-الاعتماد على متخصصين في عدد كبير من الموضوعات وخاصة في بعض الجامعات

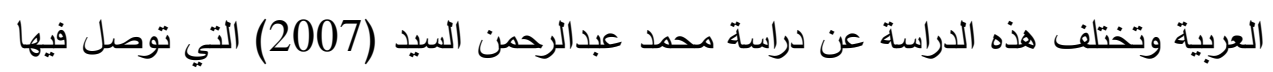
إلى عدم وجود كوادر صحفية متخصصة في مجال الإعاقة.

2-استخدام الألوان بشكل واضح واستخدام الصور والرسومات في تتاول الموضوعات الإعل فيهات

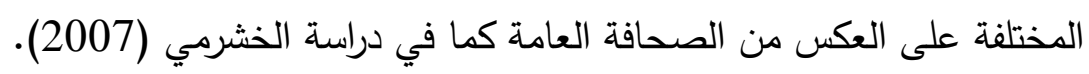

$$
\text { 3-الاتجاه الإيجابي في تناول قضايا ومشكلات ذوي الإعاقة. }
$$

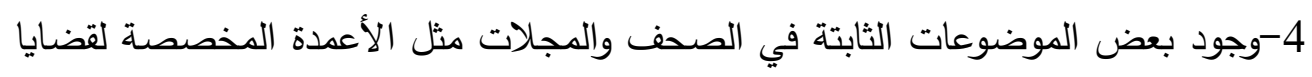
الإعاقة كما هو الحال في مجلة رسالة الجامعة في جامعة الملك سعود.

5- من مظاهر القوة لاى بعض الصحف زيادة الموضوعات بشكل متوازن في مختلف الأعداد مثل جامعة الملك سعود.

$$
\text { ويمكن ملاحظة جوانب الضعف فيما يلي: }
$$

1-عدم التوازن في الاهتمام بمختلف الفئات فهناك فئات مثل الصحية كان الاهتمام بها واضحا وهناك فئات مثل صعوبات التعلم والاضطرابات السلوكية والتوحد كان الاهتمام بها ضعيفا. 
r-عدم الاهتمام بقضايا الحقوق بنفس الكيفية التي تم تتاول قضايا التوعية والتعليم والتدريب بل تم إهمال القضايا الاجتماعية التي تمس عدد كبير من ذوي الإعاقة وخاصة في السنوات النهائية من الدراسة الجامعية مثل قضايا التوظيف والزواج وغيرها. r-عدم استخدام التحقيق والمقال بثكل كاف حيث حصلا على نسب ضعيفة في مختلف الصحف الجامعية.

ع -عدم إبراز قضايا الإعاقة في الصفحات الأولى والأخيرة في جميع الصحف الصادرة وتتفق هذه الدراسة مع دراسة سحر الخشرمي (2007) هـ-هناك بعض الصحف تصدر العديد من الأعداد ولم تتناول فيه موضوعا واحدا مثل مجلة جامعة الثارقة.

צ-عدم إشراك عدد من الطلاب ذوي الاحتياجات الخاصة في هيئة التحرير أو في الأعمدة الثابتة أو حتى بشكل دوري حيث هناك صحف لا تهتم بذلك بشكل واضح ويظهر ذلك فئل في جميع الصحف الصادرة عدا جامعة الملك سعود. V-عدم تحقيق التعاون بين المتخصصين في أقسام التربية الخاصة وهيئات التحرير في

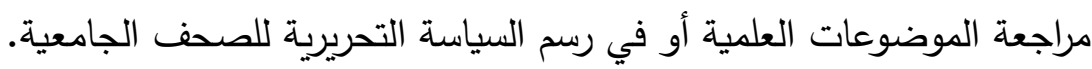
^- قلة الموضوعات التي تتحدث عن ذوي الإعاقة في كثير من الصحف الجامعية عدا جامعة الملك سعود وجامعة الأردن. 9-عدم وجود استراتيجية محددة وواضحة لهذه الصحف يتم تتاول قضايا ومشكلات وهموم ذوي الإعاقة من خلالها والاكتفاء فقط بالمناسبات لعرض موضوعات ذوي الاحتياجات الخاصة وتتفق هذه الدراسة مع دراسة (محمد عبدالرحمن السيد ، 2007)

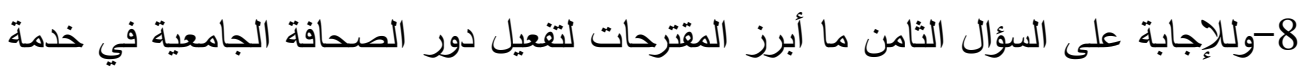
قضايا الإعاقة؟ من خلال تحليل نتائج الدراسة السابقة وما جاء في دراسات وأبحاث وأوراق عمل خاصة بقضايا الإعلام والإعاقة يمكن ملاحظة أن بعض الجامعات العربية أسندت مهمة إصدار

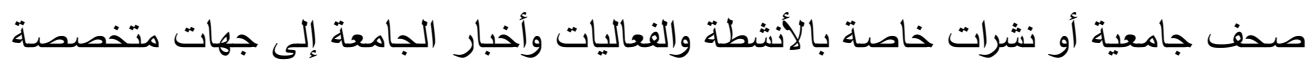

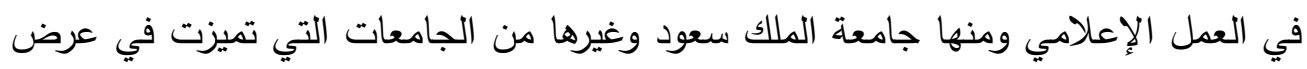

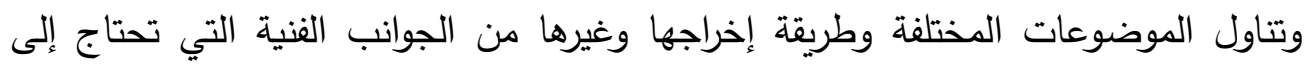


متخصصين في الجانب الإعلامي مثل أساتذة كليات الإعلام ويمكن أن نستقيد من هذه

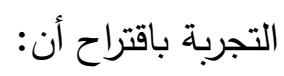

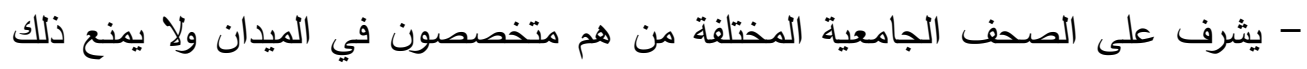

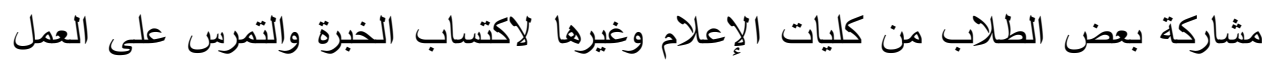

$$
\text { الإعلامي. }
$$

- تقترح الدراسة أن يكون ضمن هيئة التحرير أو فريق العمل المستشار العلمي المتخصص

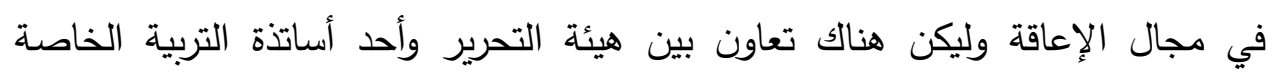

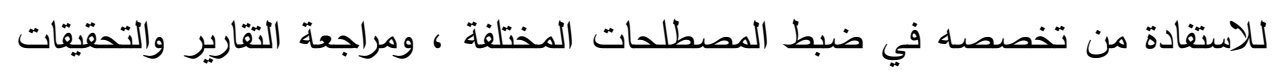

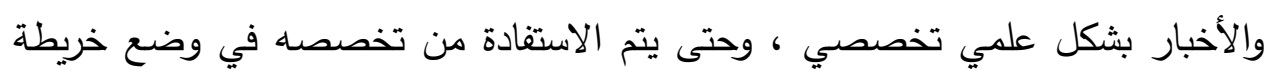

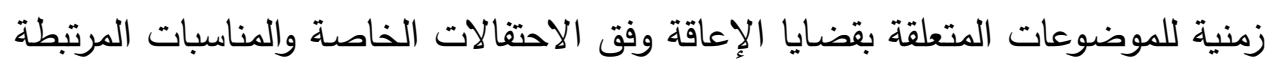

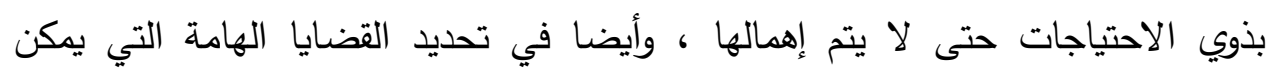

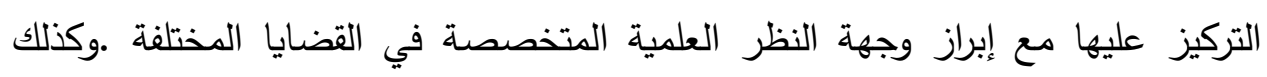
ليسهم في صياغة الأخبار المختلفة ،وحرصا على توجه هذه الصحف وتقويم دورها بصورة مستمرة . - يفضل في الصحف الجامعية أن يكون هناك أبوابا ثابتة تتناول موضوعات متعلقة بفئات

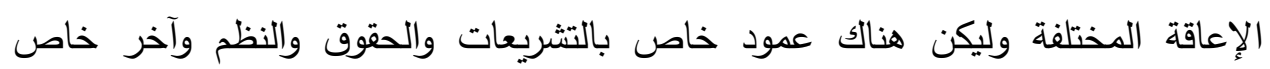
بالجوانب الصحية والطبية وآخر خاص بالقضايا الاجتماعية وغيرها.

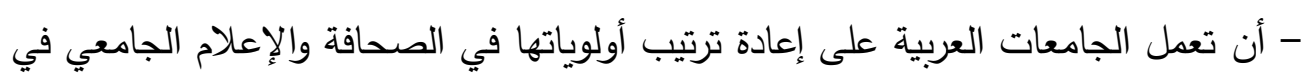
تتاولها لقضايا ومشكلات وموضوعات الإعاقة حيث يلاحظ أن الصحافة بشكل عام لديها

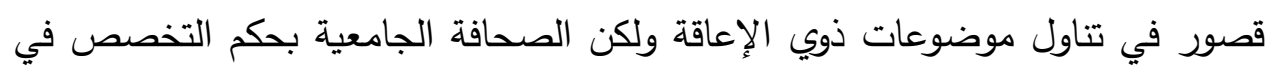

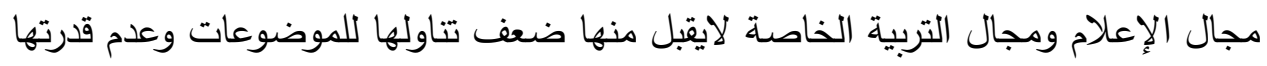
على تقديم نماذج متميزة في عرض وتتاول موضوعات ذالإل ذوي الإعاقة.

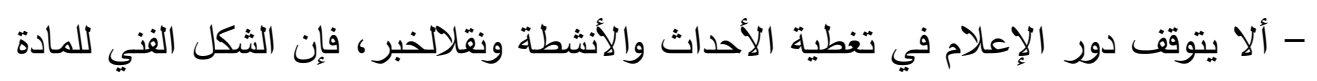

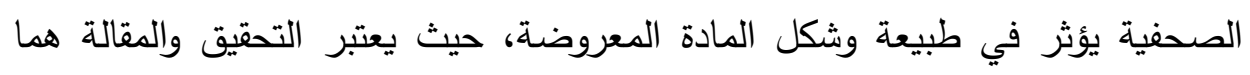

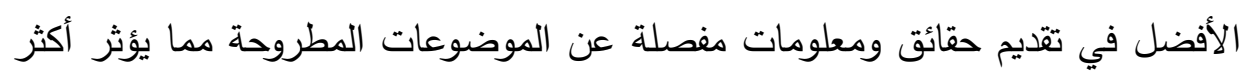

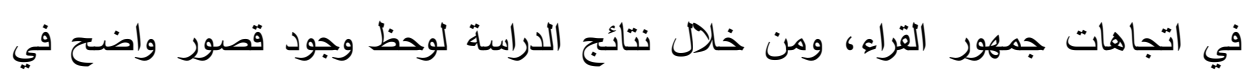


المقالات والتحقيقات حيث إن الأخبار والتقارير حازت على أعلى نسبة في الثكل الفني

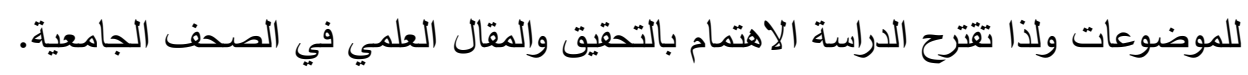
- تخصيص صفحة متخصصة بالصحف الجامعية تهتم بقضايا الإعاقة والمعاقين، وتقوم على شراكه والتحام فعلي بواقع المعاقين وأسرهم،ومؤسساتهم، والعاملين معهم.

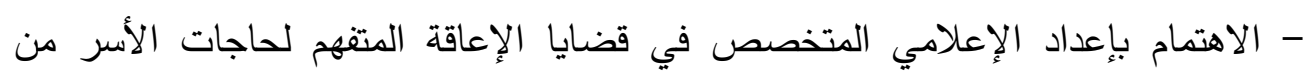
طلاب كليات الإعلام أو غيرها من التخصصات المناسبة.

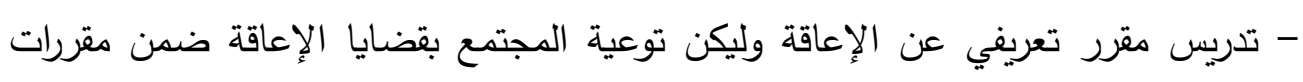

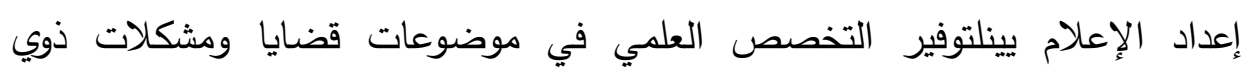
الاحتياجات الخاصة.

- مراعاة التوازن في الاهتمام بفنون التحرير الصحفي في تتاول موضوعات الإعاقة، خاصة فن التحقيق والحديث الصحفي بدلا من التركيز على المواد الإخبارية والمقالات.

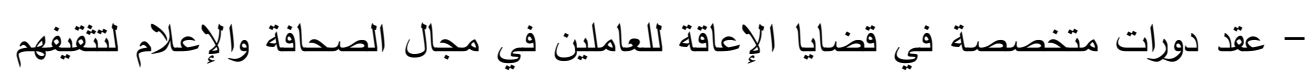
علميا ولتعديل الاتجاهات السلبية تجاه المعاقين وضبط المصطلحات العاتعات للعية. بحوث مقترحة:

تقترح الدراسة عمل دراسة لتحليل مضمون قضايا الإعاقة في بعض المجلات المتخصصة بالإعاقة. تقترح الدراسة تحليل مضمون لقضايا الإعاقة لبعض المواقع الإلكترونية الخاصة بذوي الاحتياجات الخاصة مثل أطفال الخليج. 
1 - اتفاقية حقوق الأشخاص ذوي الإعاقة الأمم المتحدة 2007. r- همام ، أحمد (2013) دور الإعلام في تتاول قضايا الإعاقة والمعاقين في دولة الإمارات العربية المتحدة ، مجلة المنال تاريخ الدخول 1436/7/3 الموقع الإليكتروني : almanal.ae/author/ahmedhamam r- إخبار الجامعة، جامعة الشارقة، تاريخ الدخول 2014/10/1 الموقع الإلكتروني https://www.google.com.sa/search?safe=strict\&q ـ - معاجيني، أسامة (1995) الوقاية من الإعاقة من منظور إسلامي، دار النشر : الكويت.

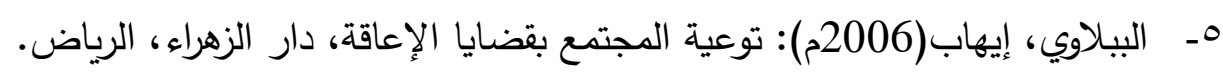

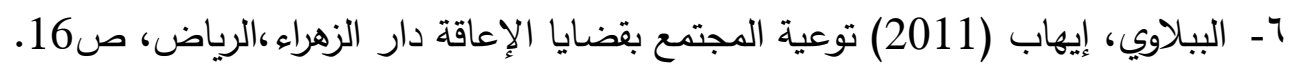

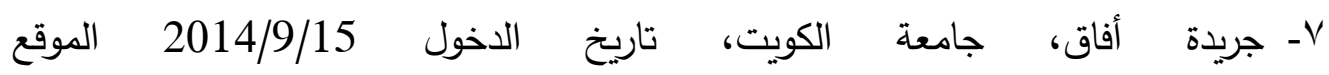

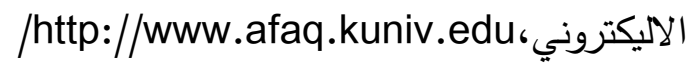
ᄉـ الخطيب، جمال،الحديدي، منى (2008): تعليم الطلبة ذوي الحاجات الخاصة في في

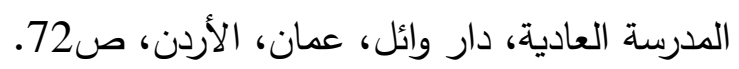
9 - الخطيب، جمال، الحديدي، منى (2015) مناهج وأساليب التدريس في التربية الخاصة،

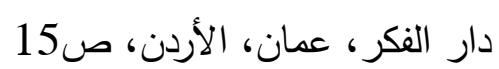
10-الحلوة، خالد (2012) الإعلام الجديد وتأثيراته في تثكيل الرأي العام. 11-الجمال، رباب (2008) العوامل المؤثرة في استقبال الصحف الجامعية دراسة تحليلية وميدانية،العوامل المؤثرة في استقبال الصحف الجامعية دراسة تحليلية وميدانية، المجلة

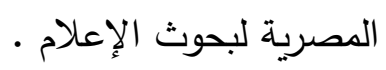
12-الخشرمي، سحر ( 2007م) التغطية الصحفية العربية لقضايا الإعاقة اليوم العالمي للطفل المعاق نموذجا.

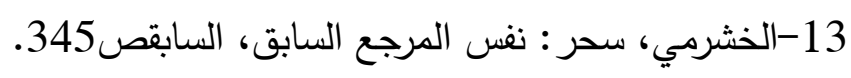


14-الصادق، سحر (2008) رؤية أصحاب الاحتياجات الخاصة لدور الصحافة، وتأثيراتها عليهم في ظل نظرية المسئولية الاجتماعية.تاريخ الدخول 2015/4/20 موقع إليكتروني http://dalya6848.blogspot.com/2014/04/35.html 15-القحطاني، سعيد (2010) اتفاقية حقوق الأثخاص ذوي الإعاقة الأمم المتحدة 2007،

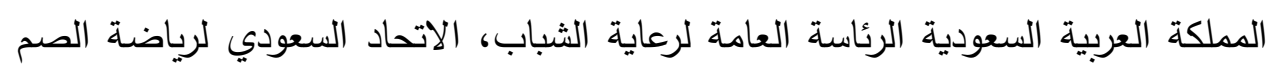
ص

16-حسين، سمير (1983)، تحليل المضمون، القاهرة عالم الكتب. 17-فاضل، سها (2002) دور الصحافة المصرية في ترتيب أولويات القضايا الدينية لدى

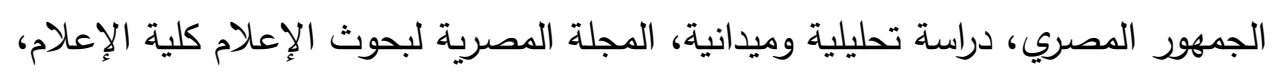

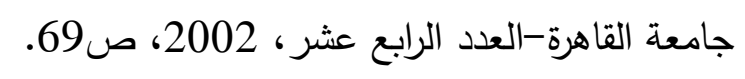

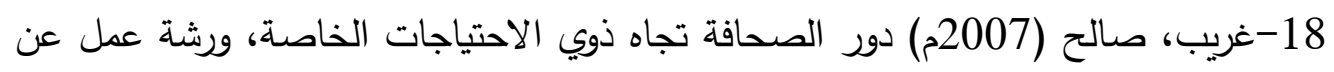

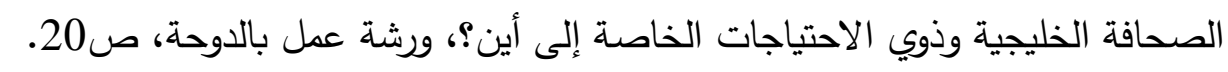

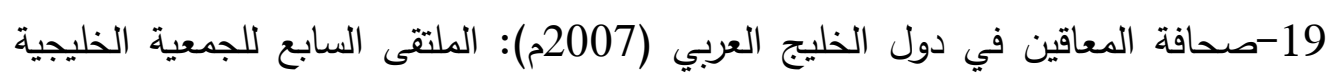

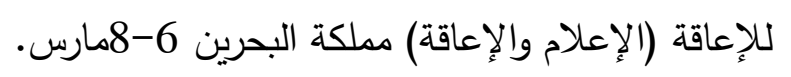
http://mu.edu.sa/ar 20 21-صحيفة إثراقه الجامعة، جامعة الملك فيصل، تاريخ الدخول 2014/10/1 موقع

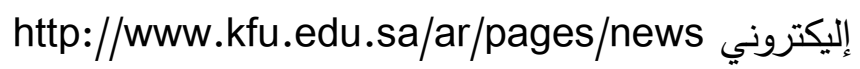
22-صحيفة أخبار الأردنية الجامعة الأردنية، تاريخ الاخول 2010/10/7 موقع http://www.ju.edu.jo/NewsLetter.aspx?Issue=April\%20 اليكتروني 2014 23-صحيفة الإعلام، جامعة حائل تاريخ الدخول 2014/9/23موقع اليكتروني، /http://www.uoh.edu.sa 24-صحيفة الجامعة، جامعة شقراء، تاريخ الدخول 2014/9/21 موقع إليكتروني http://www.su.edu.sa/MediaCenter/Universitynewspaper 25-عرفة، عبدالباقي (2012) توعية المجتمع بالإعاقة، الأنجلو المصرية، القاهرة، ص20 
26-عبدالحميد محمد (2004) البحث العلمي في الدراسات الإعلامية، ط2، عالم الكتب القاهزة

27-المقوشي، عبدالعزيز (2000) قايا الإعاقة في الصحافة السعودية، مركز الأمير سلمان لأبحاث الإعاقة، الرياض. عالعزيز

28-العبدلي، عبيد (2011) مقال منشور على مدونته بتاريخ 2011/1/1 عنوان موقع

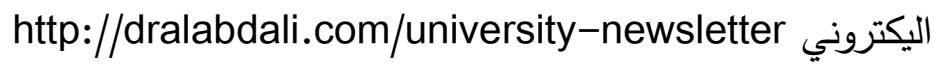

29-القرني، على (2014) مقال بجريدة الجزيرة بعنوان الصحافة الجامعية إلى أين،بتاريخ http://www.al-

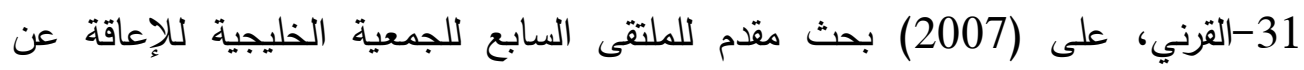

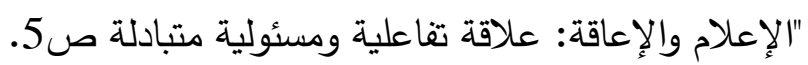
32-حسنة، عمر (2012) رؤية إعلامية للأشخاص ذوي الاحتياجات الخاصة 33-خضر، عمر (1993): الإعلام وحقوق المعاقين، ندوة حقوق المعوقين،الثارقة، دائرة الثقافة والإعلام.

34-الروسان، فاروق(1998) قضايا ومشكلات في التربية الخاصة، دار الفكر للطباعة

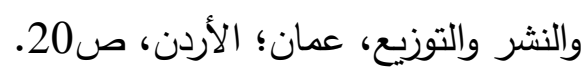

35-المغلوث، فها(1999) رعاية وتأهيل المعوقين في الملكة العربية السعودية. الرياض:

مكتبة الملك فهز الوطنية.

36-ليفين، ليا(1986) حقوق الإنسان أسئلة وأجوبة، دار المستقبل العربي،القاهرة،مصر • 37-عبد المجيد، ليلى (1997) العوامل المؤثرة على تحرير الصحف الجامعي، المجلة

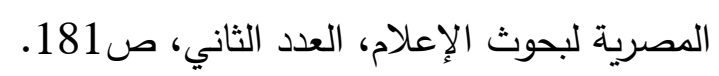

38-مجلة أفاق الجامعة،جامعة البحرين، تاريخ الدخول 2014/8/22 موقع اليكتروني ، http://www.uob.edu.bh/uob 39-مجلة الزميل جامعة بيروت العربية تاريخ الدخول 2014/10/1، موقع إليكتروني /http://www.alzamilmagazine.com 
40-مجلة جامعة الأمام (1429هـ) العدد التاسع شهر شوال، ص333 إلى ص375 41-مجلة رسالة جامعة الملك سعود تاريخ الدخول 2014/9/25 موقع إليكتروني /http://rs.ksu.edu.sa

42-السيد، عبدالرحمن (2007م) : الصحافة الخليجية وذوي الاحتياجات الخاصة إلى أين ، ورقة مقدمة للملتقى السابع للجمعية الخليجية للإعاقة (الإعلام والإعاقة ) مملكة البحرين

$$
\text { 43-السيد، عبد الرحمن: مرجع سابق ص15 } 8 \text { مارس }
$$

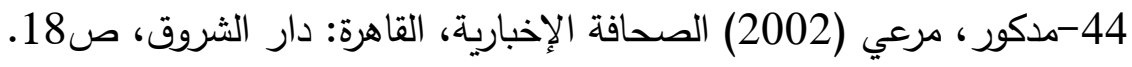

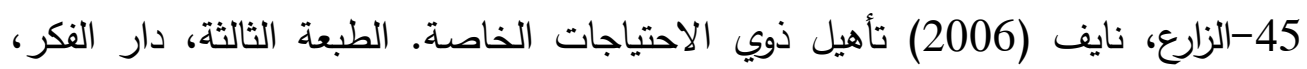
عمان، الأردن.

46-حسونة، نسرين (2014م): تحليل المضمون محدداته ومفاهيمه، موقع الألوكة 47-نشرة المسار، جامعة السلطان قابوس 1، ناريخ الدخول /2014/9، موقع اليكتروني، http://www.squ.edu.om/puplic-relation-ar/tabid/9659/language/enUS/Default.aspx 48-نشرة خدمة المجتمع وتتمية البيئة، جامعة القاهرة تاريخ الدخول 2014//21 http://cu.edu.eg/ar/Journal اليكتروني 49-نشرة شؤون الطلاب، جامعة قطر ، تاريخ الدخول 2014/9/21، تاريخ الدخول موقع Khttp://www.shaqramaga.com/index.php اليكتروني جتئسون 50-الزعمط ، يوسف (2005) .التأهيل المهني للمعوقين. عمان: دار الفكر للنشر والتوزيع. 
51-Antrim, Debra, (1997). Newspaper Coverage of Learning Disabilities, Journal of Education, Volume 118.

52-Cutcliffe, J. and B. Hannigan,(2004) "Mass Media, "Monsters" and Mental Health clients", Journal of Psychiatric and Mental Health Nursing, 8:4, pp. 315-21, in Dara R. Edney, "Mass Media and Mental Illness: A Literature Review" Canadian Mental Health Association, Ontario, January 2004

53-Fara. M. goulas and others,(2003) making inclusion work in rural sat east texax 2003 page 1-15 http:// www.international journal of special education 4/5/2006

54-Hardin, Brent. Hardin Marie. Lynn, Susan Walsdrof, Kristi.( 2000). Missing In Action: Images of Disability in Sports Illustrated for Kids. Disabilities Studies Quarterly: 21, 2001

55- Haller, Beth,(1999) "News Coverage of Disability Issues", The Center for An Accessible society, July 1999, www.accessiblesociety.org. Haller, Beth, " Balancing Acts: Government, Business and Disability Sources in the News Representations of the ADA". Paper presented in the Annual Conference of the Association for Education in Journalism and Mass Communication, 1996

56--Harpe, Wendy and Carol Malcolm,(2005) "Not Seen, Not Heard: Learning Disabled Audiences and the Media", BBC Diversity Center, p. 33

57-Hegarty etal..(19781) "Children with Special need's in ordinary school" National Foundation for Education Research.

58-Kauffman, Etal, : Mainstreaming(1973) Toward on Explication of The Construct. In Mayan E. Etal. (Ed)., Alternatives for Teaching Exceptional children, Denever, Colo: Love.

59--Parker, Elliott(1996). . Balancing Acts: Government, Business, And Disability Sources In News Representations Of The ADA.

60- Marie. Lynn, Susan. Walsdrof, Kristi.( 2000). Missing In Action: Images ofDisability in Sports Illustrated for Kids. Disabilities Studies Quarterly:

61--Yoshilda, Roland, Wasilewski, Lynn, Douglas ,Friedman (1990).Recent News Papers Coverage About Persons with Disabilities. Journal of exceptional children, Volume.56.Issue 